\title{
Photovoltaic Incentive Design Handbook
}

Subcontract Report NREL/SR-640-40845

December 2006

T.E. Hoff

Clean Power Research

Napa, California

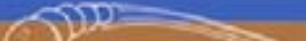




\section{Photovoltaic Incentive Design Handbook}

T.E. Hoff

Clean Power Research

Napa, California

NREL Technical Monitor: R. Margolis

Prepared under Subcontract No. ADC-6-66286-01

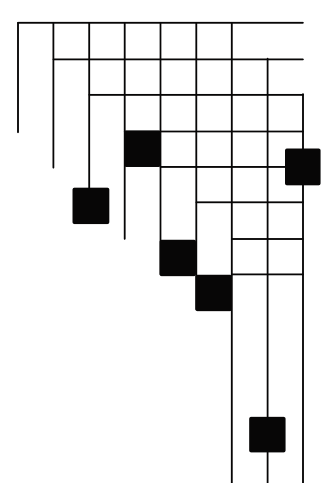




\section{NOTICE}

This report was prepared as an account of work sponsored by an agency of the United States government. Neither the United States government nor any agency thereof, nor any of their employees, makes any warranty, express or implied, or assumes any legal liability or responsibility for the accuracy, completeness, or usefulness of any information, apparatus, product, or process disclosed, or represents that its use would not infringe privately owned rights. Reference herein to any specific commercial product, process, or service by trade name, trademark, manufacturer, or otherwise does not necessarily constitute or imply its endorsement, recommendation, or favoring by the United States government or any agency thereof. The views and opinions of authors expressed herein do not necessarily state or reflect those of the United States government or any agency thereof.

Available electronically at http://www.osti.gov/bridge

Available for a processing fee to U.S. Department of Energy and its contractors, in paper, from:

U.S. Department of Energy

Office of Scientific and Technical Information

P.O. Box 62

Oak Ridge, TN 37831-0062

phone: 865.576 .8401

fax: 865.576 .5728

email: mailto:reports@adonis.osti.gov

Available for sale to the public, in paper, from:

U.S. Department of Commerce

National Technical Information Service

5285 Port Royal Road

Springfield, VA 22161

phone: 800.553.6847

fax: 703.605.6900

email: orders@ntis.fedworld.gov

online ordering: http://www.ntis.gov/ordering.htm 


\section{Executive Summary}

Investments in customer-owned grid-connected photovoltaic (PV) energy systems are growing at a steady pace. This is due, in part, to the availability of attractive economic incentives offered by public state agencies and utilities. In the United States, these incentives have largely been upfront lump payments tied to the system capacity rating.

While capacity-based "buydowns" have stimulated the domestic PV market, they have been criticized for subsidizing systems with potentially poor energy performance. As a result, the industry has been forced to consider alternative incentive structures, particularly ones that pay based on long-term measured performance. The industry, however, lacks consensus in the debate over the tradeoffs between upfront incentive payments versus longer-term payments for energy delivery.

\section{Objective}

This handbook is designed for agencies and utilities that offer or intend to offer incentive programs for customer-owned PV systems. Its purpose is to help select, design, and implement incentive programs that best meet programmatic goals. The handbook begins with a discussion of the various available incentive structures and then provides qualitative and quantitative tools necessary to design the most appropriate incentive structure. It concludes with program administration considerations.

\section{Results}

Two structures emerge as being particularly attractive. One is a performance based incentive (PBI) and the other is an expected performance based buydown (EPBB). A PBI makes multiple payments over a longer period of time, based on actual, measured energy production by the system. An EPBB makes a single upfront payment based on expected system performance.

Both a PBI and an EPBB can address one-time issues that have the potential to affect system output. These one-time issues include system rating (based on equipment and installation), system design (based on orientation, shading), and geographical location. Each of these structures, however, has strengths and weaknesses.

PBI exceeds EPBB's ability to guarantee energy production because it captures the effect of recurring issues, such as dirt accumulation, module degradation, and inverter failure as well as year-to-year weather variations. The PBI, however, is likely to have higher administrative costs due to its longer duration, and it does not address the initial capital investment barrier as well as the EPBB.

The EPBB exceeds the PBI's ability to address the initial capital investment barrier without relying on external financial resources, and it is likely to have simpler program administration. Unlike the PBI, however, the EPBB cannot guarantee long-term system output because it can only address one-time performance factors. 
A clean energy program's selection of the incentive structure will depend upon the program's goals, constraints, and beliefs about where the potential performance problems will occur and program administration costs. Depending upon the size of the program, it may be desirable for a program to implement multiple structures simultaneously. 


\section{Acknowledgments}

This handbook represents the efforts by people at a number of agencies, companies, and utilities. Some have performed or sponsored research and analysis while others have been involved in commenting on results at various stages of the work. They include Americans for Solar Power, Arizona Corporation Commission, BP Solar, BEW Engineering, California PV Utility Program Managers, California Energy Commission, California Public Utilities Commission, Cal SEIA, Energy Ideas, Kyocera Solar, Lawrence Berkeley Labs, National Renewable Energy Laboratory, Northwest Solar Center, Prometheus Institute, PV Now, The Rahus Institute, Renewable Ventures, Salt River Project, Sacramento Municipal Utility District, SEIA, Segue Consulting, Sharp Solar, Spectrum Energy, Solar Electric Power Association, SPG Solar, SunEdison, Vote Solar, and others.

While many people provided comments on all or portions of this Handbook, very detailed review and other comments were provided by Ben Norris (Norris Energy Consulting), Sue Gouchoe (North Carolina Solar Center), Karlynn Cory (National Renewable Energy Laboratory), and Karl Knapp (City of Palo Alto). Any errors or omissions are the responsibility of the author.

This Handbook was prepared with support from DOE/NREL Subcontract No. ADC-666286-01. 


\section{Table of Contents}

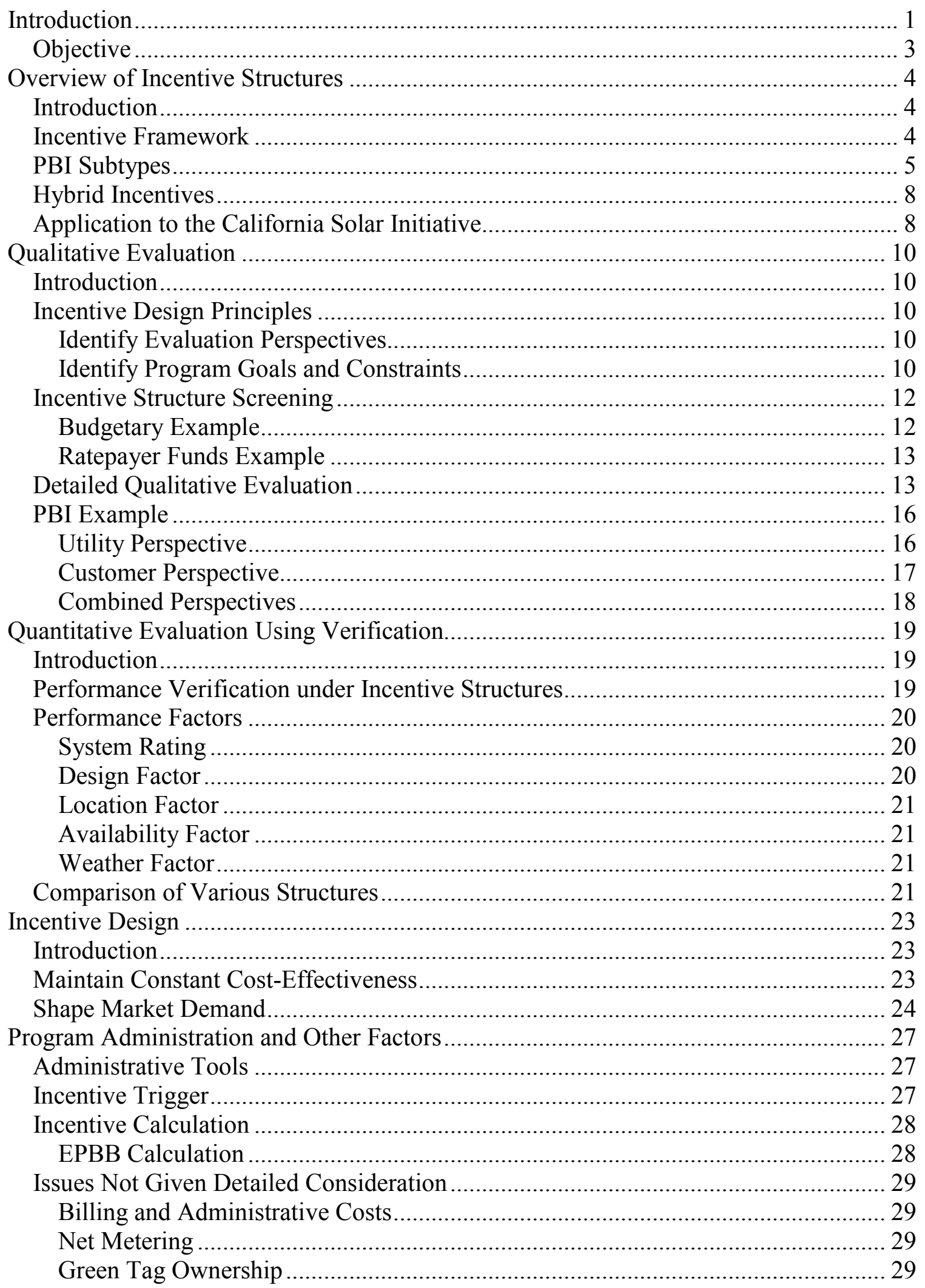




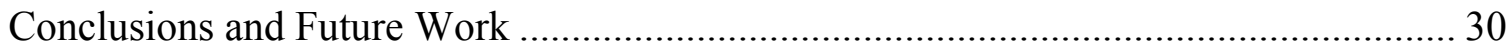

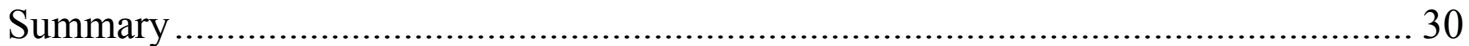

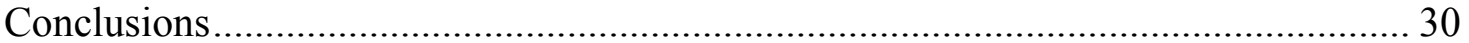

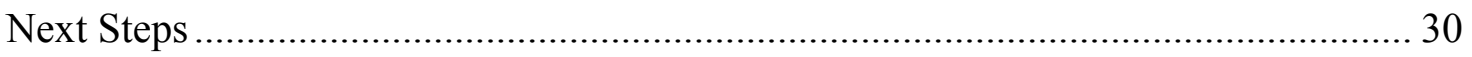

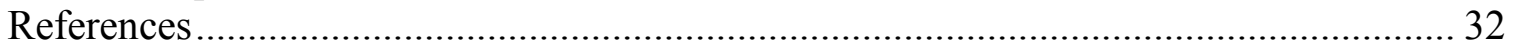

Appendix A: Performance-Based Elements in PV Incentive and REC Programs ........... 34

Appendix B: Verification Provided by Incentive Structures ........................................ 39

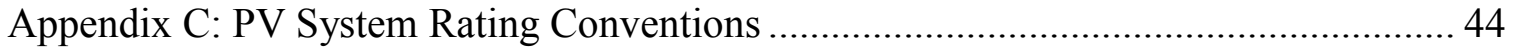

Appendix D: Incentive Design That Maintains Constant Cost-Effectiveness .................. 46

Appendix E: Incentive Design That Shapes Market Demand ..................................... 58

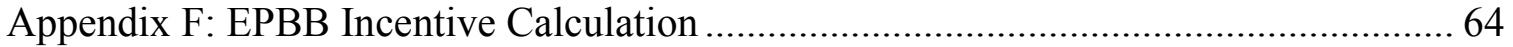




\section{List of Figures}

Figure 1. Sample of PBI structures in the U.S. ......................................................... 2

Figure 2. Incentive framework and structure classifications. ........................................ 5

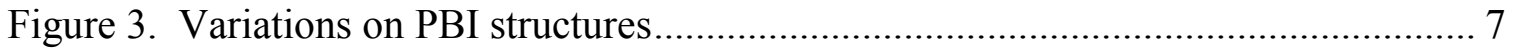

Figure 4. Expanded incentive framework and structure classifications. ......................... 8

Figure 5. California Solar Initiative proposals..................................................... 9

Figure 6. Annual budget expenditures for hypothetical program............................... 13

Figure 7. PBI structure establishes the interaction between utility and the customer. .... 16

Figure 8. Utility perspective: PV system performance is a critical uncertainty. ............. 17

Figure 9. Customer perspective: customer makes decision to buy now or to wait.......... 18

Figure 10. Incentive level using calendar-based trigger. ......................................... 25

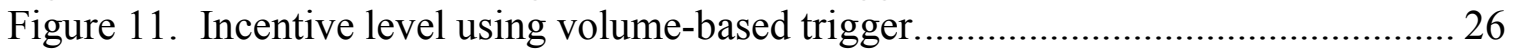

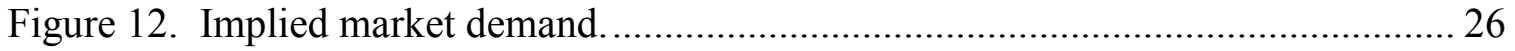

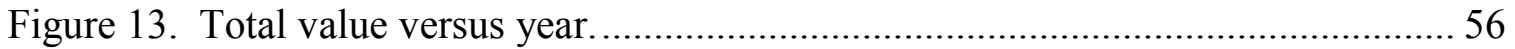

Figure 14. Incentive administered on a volume basis for model and Joint Filing results.62

\section{List of Tables}

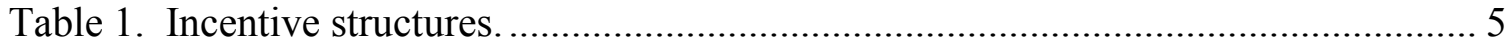

Table 2. Qualitative assessment of attributes for various structures:.......................... 15

Table 3. Ability of structures to account for factors that affect system performance...... 22

Table 4. Proposed CEC new homes incentive structure. ............................................... 25

Table 5. Performance-based elements in PV incentive and REC programs................... 35

Table 6. Cash flows associated with two investment alternatives................................ 48

Table 7. Difference between "Buy Now" versus "Wait 1 Year" cash flows.................. 48

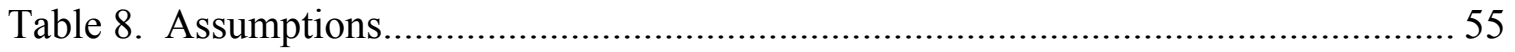

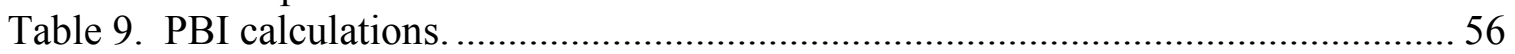

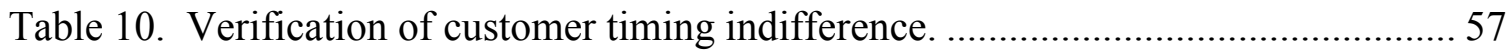

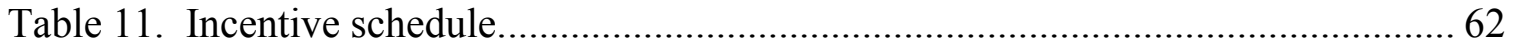

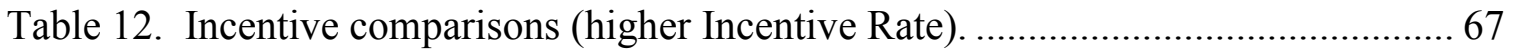

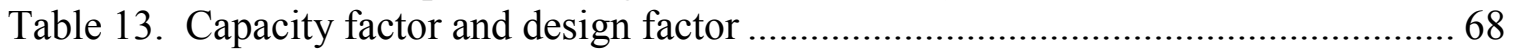

Table 14. Incentive comparisons (Reference System is horizontal w/ shading). ............68 


\section{Introduction}

Investments in customer-owned grid-connected photovoltaics (PV) have been growing at a steady pace for several years. PV delivers clean, renewable electricity to the customer and the power grid, and provides a number of benefits to utilities and electric ratepayers. PV offsets the costs of power generation and T\&D infrastructure, lowers domestic fuel consumption, has environmental benefits, and provides a hedge against future fuel price volatility. The technology is highly reliable with an exceptionally long service life, and it is virtually maintenance-free. PV has the potential to dramatically change the way electric power is generated and distributed throughout the world.

The principal barrier to widespread adoption of PV is the high capital cost. While prices are on a downward trend, most commercial and residential customers are not able to justify the cost through utility bill savings alone. Many public state agencies and utilities in the U.S. recognize that prices will drop as production and installation experience is increased and have established monetary incentive programs to make systems cost competitive for the customer.

Most of these incentive programs pay upfront incentives based on system capacity. This Handbook refers to these incentives as capacity-based buydowns (CBB). A criticism directed at $\mathrm{CBB}$ incentives is that they do not motivate effective system design, efficient component selection, or the owner to establish regular maintenance once the project is installed. As a result, there has been a growing interest in performance based incentives (PBI). Unlike CBBs, PBIs reward system performance by paying on the basis of actual energy produced.

A range of PBI structures have been implemented in the U.S. Figure 1 presents a sample of the structures. For example:

- California Energy Commission's pilot program pays a constant rate of $50 \notin$ per $\mathrm{kWh}$ over the duration of 3 years,

- We Energies (Wisconsin) pays a constant rate of $22.5 \notin$ per $\mathrm{kWh}$ for a duration of 10 years, and

- New Jersey's Clean Energy Program (as well as other programs) offers a capacity-based incentive plus the payment of market-based Renewable Energy Credits that do not have a fixed duration or rate.

Appendix A provides details for additional performance-based programs and references $[2],[3],[5]$, and [6] contain results from other studies. A detailed review of programs is available in [17]. 


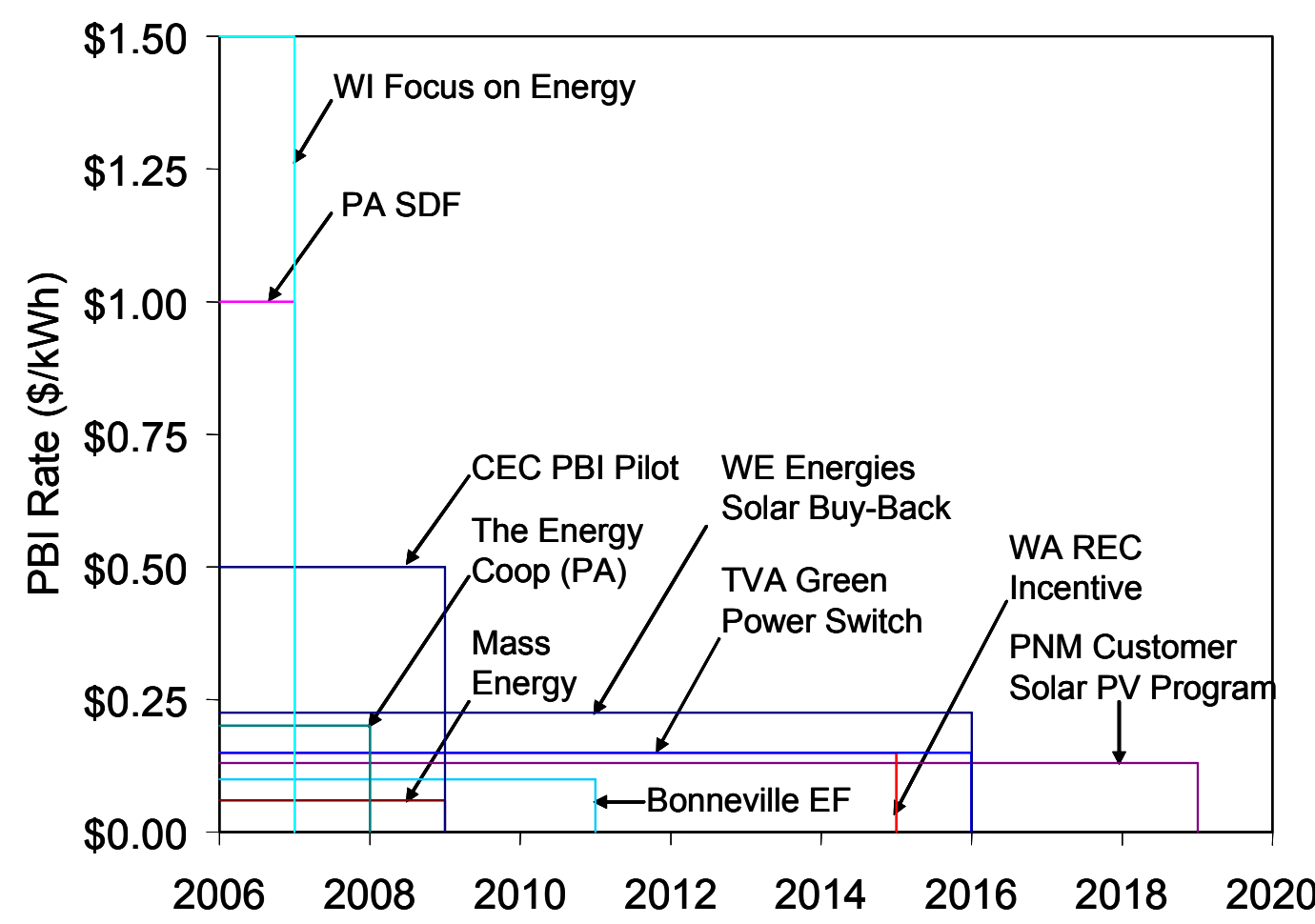

Figure 1. Sample of PBI structures in the U.S. ${ }^{1}$

The lack of consistency across these programs and studies suggest that there is little industry consensus in addressing "best practice" questions such as:

- What should the PBI rate be to provide customers with an adequate return?

- Should the PBI be paid out over 1 year? 3 years? 5 years? 10 years? 20 years?

- Should the PBI be constant or vary over time?

- Should the PBI structure change for new customers in subsequent years?

- How should the PBI vary for different regions with different resources?

One of the motivations to move to a PBI structure is that the German feed-in $\operatorname{tariff}^{2}$ (a form of a PBI) has successfully stimulated the growth of the world's largest PV market. There is a difference, however, between the German-style PBI and the PBIs that are typically being implemented in the U.S. The feed-in tariff is the sole means of revenue for PV owners in Germany while PV owners in the U.S. typically receive the combined economic benefits of utility bill savings and incentive payments. Under the U.S. model, the utility bill savings already provides a performance-based benefit.

\footnotetext{
${ }^{1}$ The WA REC incentive can be significantly higher by carefully selecting locally produced equipment.

${ }^{2}$ The German "Feed-in Law" (2004) compensates solar generation for ground installations at 45.7 euro cents per kWh $(\$ 0.585)$ and building mounted systems at 57.4 euro cents per kWh $(\$ 0.735)$. See www.solarbuzz.com/FastFactsGermany.htm for more details.
} 
As a result of these and other factors, there is an industry debate as to the tradeoffs between upfront incentives and incentives tied to production. This debate is occurring at small programs and large incentive programs, including the California Solar Initiative (CSI).

While the $\mathrm{CBB}$ provides capital to lower investment cost, manage capital risk, and lower financing requirements, it does not promote performance. While the PBI promotes performance, it does not relieve the capital cost barriers. In response to this dilemma, a hybrid structure has been proposed called the expected performance based buydown (EPBB). The EPBB is an upfront payment based on expected system performance (using such inputs as component efficiencies, design orientation, location, and weather data). These structures will be discussed in more detail, with their respective advantages and disadvantages to help decision-makers choose the system that base aligns with their programmatic objectives.

\section{Objective}

The objective of this Handbook is to assist agencies and utilities that offer or intend to offer incentive programs for customer-owned grid-connected PV systems in selecting, designing, and implementing incentives to best meet their programmatic goals.

The Handbook addresses the following topics:

- Overview of incentive structures

- Selection of incentive structures using qualitative approaches

- Selection of incentive structures using a quantitative verification approach

- Incentive design

- Program administration

Analytical models and other details are presented in the appendices. 


\section{Overview of Incentive Structures}

\section{Introduction}

Selecting an incentive structure that best satisfies the overall goals and constraints of an incentive program requires knowledge of the available types of incentives. This chapter presents a high level framework by which the various incentive structures can be classified. It demonstrates how the framework can be applied by categorizing proposals submitted by parties involved in the California Solar Initiative (CSI).

\section{Incentive Framework}

Incentive structures may be classified in terms of Payment Basis and Payment Timing. ${ }^{3}$ Payment Basis refers to the technical attribute that is rewarded, and can include equipment rating, expected system performance, or actual performance. Payment Timing refers to the timing of incentive payments, either a single upfront payment or multiple payments over time. That is, incentives are categorized within the framework as follows:

- Payment Basis

- Equipment rating (system capacity, or $\mathrm{kW}$ )

- Expected performance (derived from a combination of system capacity, installation, orientation, location, and weather assumptions)

- Actual performance (system output, or kWh)

- Payment Timing

○ One upfront payment

- Multiple payments over time

In this Handbook, each incentive type is described as a combination of the Payment Basis and the Payment Timing. In terms of Payment Basis, incentives based exclusively on system capacity include the word "Capacity", incentives based on expected performance include the words "Expected Performance", and incentives based on actual performance include the word "Performance". In terms of Payment Timing, incentives paid out as one upfront payment include the word "Buydown" and incentives paid out over time include the word "Incentive". 4

The Handbook combines these options together to result in the five incentive structures. ${ }^{5}$ These structures are described in Table $\mathbf{1}$ and are placed within the framework as shown in Figure 2. Note that combinations of these structures is also possible, such as having a portion of the payment made upfront and another portion made over time.

\footnotetext{
${ }^{3}$ The initial phases of this work categorized the incentives in terms of Payment Basis and Payment Rate [10].

${ }^{4}$ The industry currently lacks consistent standards with respect to incentive terminology.

${ }^{5}$ While a sixth incentive type is feasible - Expected Performance Based Incentive (EPBI) - it is not included in this report because it has not been encountered in practice and it is unlikely to be implemented, because payments over time can be easily based on actual performance (not just expected performance).
} 
Table 1. Incentive structures.

\begin{tabular}{|l|l|l|}
\hline Incentive Structure & Identifier & Description \\
\hline $\begin{array}{l}\text { Capacity Based } \\
\text { Buydown }\end{array}$ & CBB & $\begin{array}{l}\text { A single upfront payment based on manufacturer } \\
\text { system rating such as DC module rating or AC rating. }\end{array}$ \\
\hline $\begin{array}{l}\text { Expected } \\
\text { Performance Based } \\
\text { Buydown }\end{array}$ & EPBB & $\begin{array}{l}\text { A single upfront payment based on estimated, } \\
\text { expected long-term performance using such inputs as } \\
\text { component efficiencies, design orientation, location, } \\
\text { and weather data }\end{array}$ \\
\hline $\begin{array}{l}\text { Performance Based } \\
\text { Buydown }\end{array}$ & PBB & $\begin{array}{l}\text { A single upfront payment based on expected long- } \\
\text { term performance with periodic adjustments over } \\
\text { time based on measured system output. }\end{array}$ \\
\hline $\begin{array}{l}\text { Capacity Based } \\
\text { Incentive }\end{array}$ & CBI & $\begin{array}{l}\text { Multiple payments over time based on manufacturer } \\
\text { system rating (kW - AC or DC). The CBI is similar } \\
\text { to the CBB except that several payments are made } \\
\text { rather than a single payment. }\end{array}$ \\
\hline $\begin{array}{l}\text { Performance Based } \\
\text { Incentive }\end{array}$ & PBI & $\begin{array}{l}\text { Multiple payments over time based on measured } \\
\text { system output (kWh). }\end{array}$ \\
\hline
\end{tabular}

Payment Timing

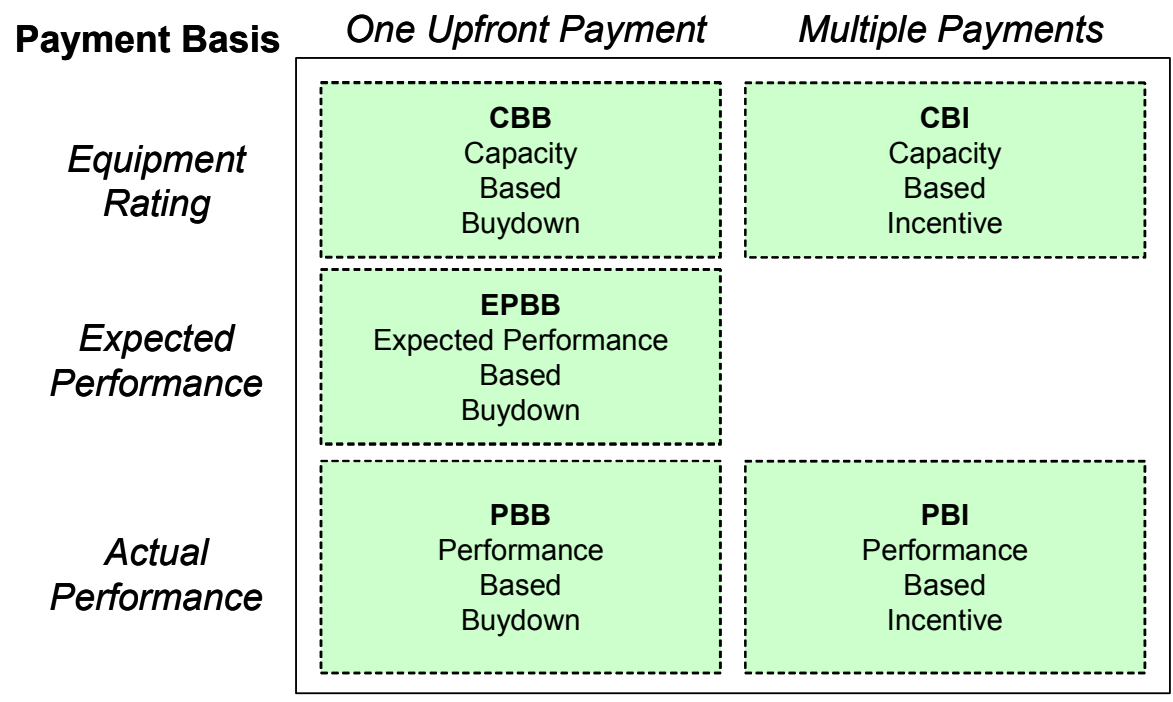

Figure 2. Incentive framework and structure classifications.

\section{PBI Subtypes}

The PBI structure has several possible subtypes. Subtypes account for differences in payment durations and payment rates for existing or new customers. For example, the terms of a PBI may specify a fixed duration where payments are made for a fixed number of years, independent of the year in which the customer invests. Alternatively it may 
specify a variable duration where all payments for a program would stop in a given year so that early investors benefit from a longer stream of payments relative to customers who invest later.

Variations of rate are possible in addition to variations of duration. A fixed rate PBI specifies a constant incentive rate across all years for a particular customer upon investment. ${ }^{6}$ A variable rate PBI specifies changes in rate over time (usually according to a predefined schedule) for a given customer.

The four possible PBI subtypes are:

- Fixed duration, fixed rate

- Fixed duration, variable rate

- Variable duration, fixed rate

- Variable duration, variable rate

These subtypes are illustrated in Figure 3 using a set of hypothetical payment rates. The black lines of each figure show the incentive, based on investment year - either 2007 (top) or 2012 (bottom). The solid yellow portions illustrate the total incentive payments to customers, over the entire incentive period in the program based on investment year. ${ }^{7}$

PBI subtypes are added to the framework as illustrated in Figure 4.

\footnotetext{
${ }^{6}$ The incentive rate for new customers, however, can still change.

${ }^{7}$ The Variable Duration, Variable Rate structure has only one line because it is the one structure that can be engineered to have a constant NPV with a rate that is independent of investment date.
} 


\section{Investment Date Highlighted}

Fixed Duration, Fixed Rate

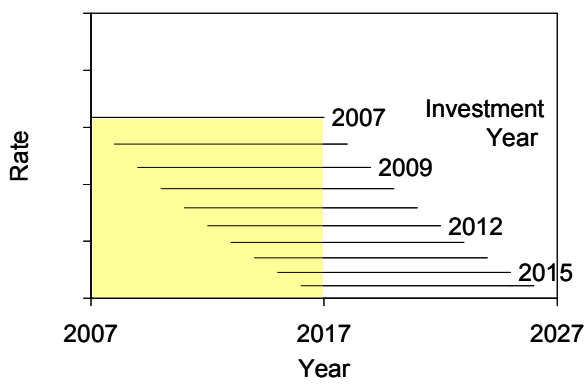

Variable Duration, Fixed Rate

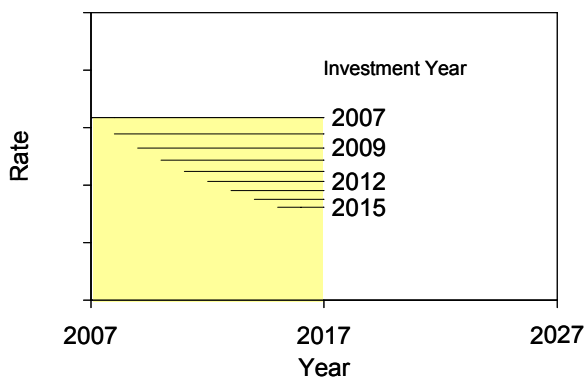

Fixed Duration, Variable Rate

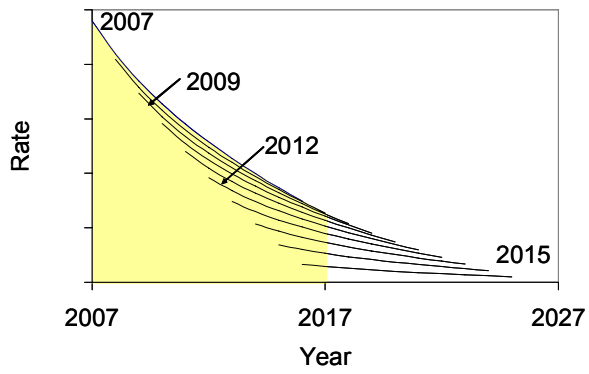

Variable Duration, Variable Rate

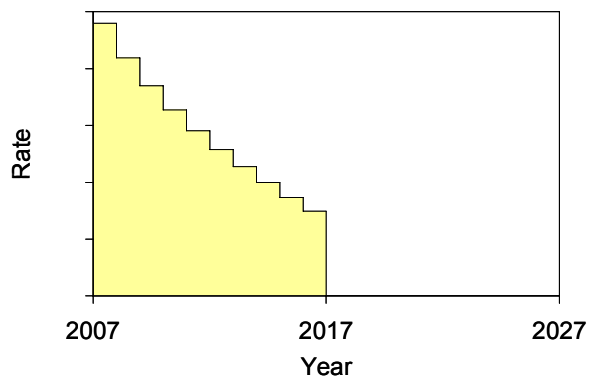

2012 Investment Date Highlighted

Fixed Duration, Fixed Rate

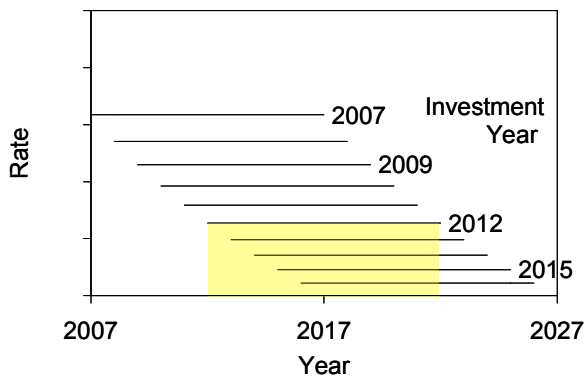

Variable Duration, Fixed Rate

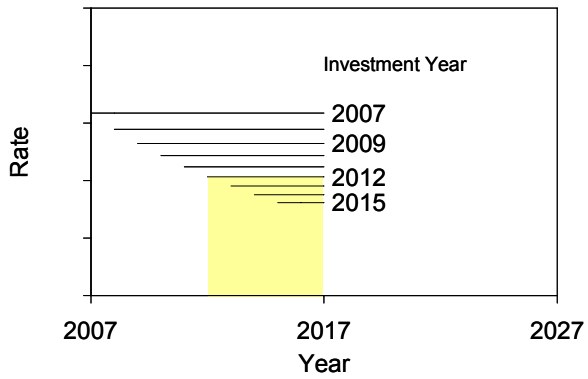

Fixed Duration, Variable Rate

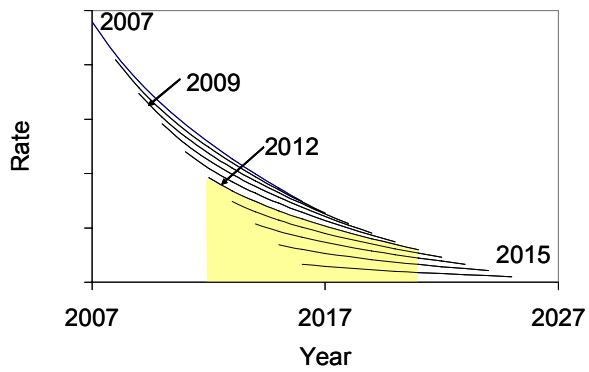

Variable Duration, Variable Rate

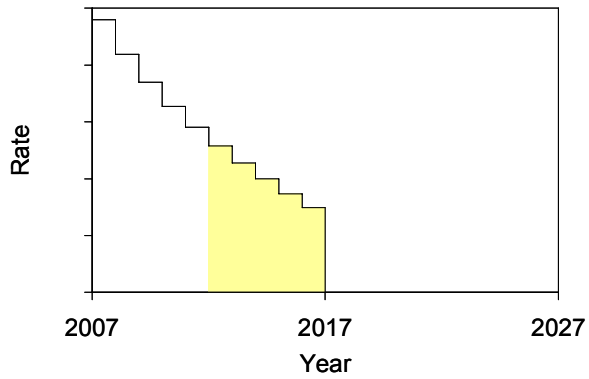

Figure 3. Variations on PBI structures (Investment payouts are shown in yellow). 


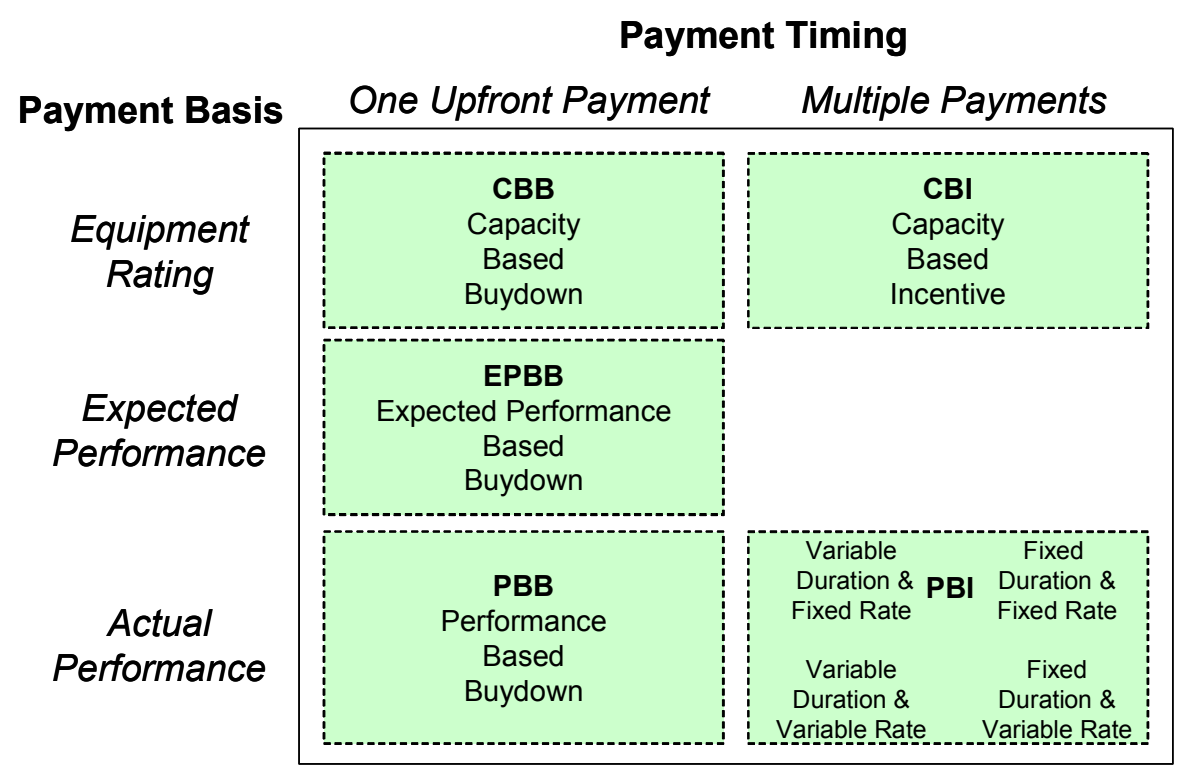

Figure 4. Expanded incentive framework and structure classifications.

\section{Hybrid Incentives}

It is also possible to combine upfront and ongoing incentive payments as a hybrid incentive. For example, the program could use a combination of an EPBB and PBI. The goal of such a program would be to capture the benefits of some upfront payments to defray capital costs, while also providing longer-term incentives that encourage proper maintenance to insure optimal system performance.

\section{Application to the California Solar Initiative}

In March 2006, a number of interested parties individually submitted proposed incentive structures to the California Public Utilities Commission for consideration under the California Solar Initiative (CSI) proceedings. Figure 5 illustrates how these proposals may be classified under the incentive framework for non-residential (top) and residential (bottom) customers. ${ }^{8}$ This illustration suggests that the framework is robust enough to capture a wide variety of the incentive structures [10].

\footnotetext{
${ }^{8}$ The dashed lines indicate hybrid proposals. For example, the PV Now proposal for non-residential customers had 75 percent $\mathrm{CBB}$ and 25 percent fixed duration fixed rate PBI. The SCE residential proposal is 50 percent $\mathrm{CBB}$ and 50 percent $\mathrm{CBI}$.
} 


\section{Non-Residential Customers}

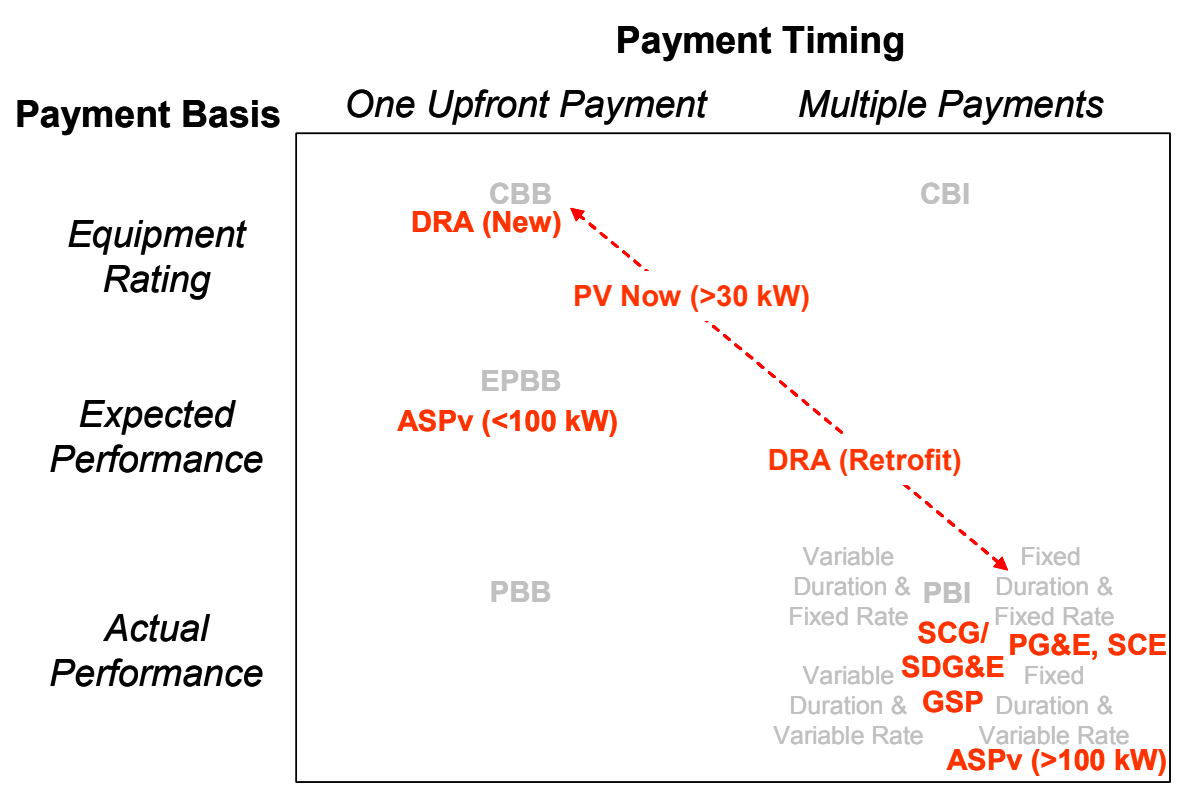

\section{Residential Customers}

\section{Payment Timing}

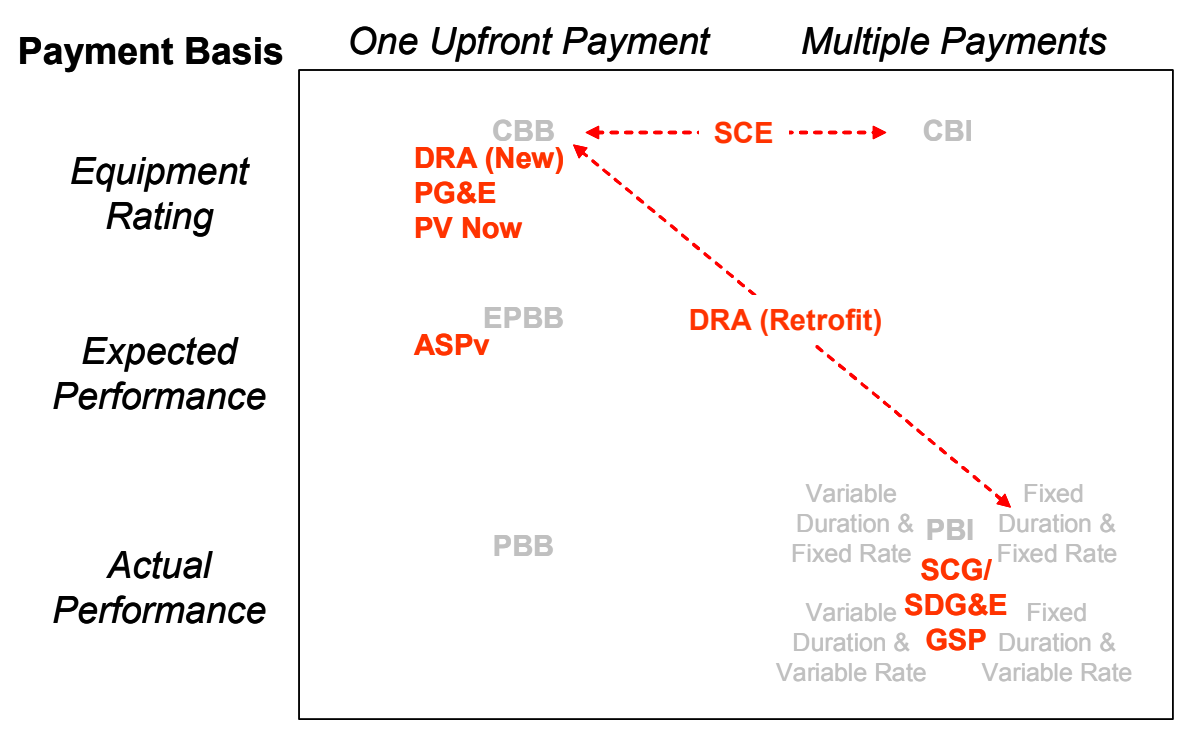

Figure 5. California Solar Initiative proposals. 


\section{Qualitative Evaluation}

\section{Introduction}

The previous chapter described five incentive structures that are available to an incentive program. They included CBB (Capacity Based Buydown), CBI (Capacity Based Incentive), EPBB (Expected Performance Based Buydown), PBB (Performance Based Buydown), and PBI (Performance Based Incentive). The structures differ in how the payments are calculated and the time frame over which the payments are made.

In considering which of the five structures would be most advantageous, the incentive agency may find that a preliminary screening will quickly rule out some of these structures due to programmatic goals and constraints. Then, a more detailed qualitative evaluation could be performed for the remaining candidate structures.

This chapter describes how to establish a set of design principals and how to perform a preliminary screening and a more detailed evaluation. Examples are provided.

\section{Incentive Design Principles}

The design of an effective incentive structure must take into account goals and constraints from the perspectives of key participating stakeholders. The collection of these different perspectives is referred to as the evaluation perspectives. This section discusses these evaluation perspectives and their associated goals and constraints.

\section{Identify Evaluation Perspectives}

The evaluation perspectives of most importance to program design need to be identified at the outset of the analysis. These perspectives might include:

- Incentive program designer (incentive agency or utility)

- Purchasing customer

- PV industry (including manufacturer and reseller)

Any or all of these evaluation perspectives might be given consideration as part of the incentive design, depending upon the focus of the incentive program.

\section{Identify Program Goals and Constraints}

Once the high priority evaluation perspectives are selected, the goals and constraints from each of the perspectives must be determined.

\section{Incentive Agency or Utility}

Consider possible goals and constraints from the incentive agency's or utility's perspective. 
Goals might include:

- Maximize the power rating (MW), energy output (kWh), or value (electrical system benefits, such as reducing congestion) of the systems installed

- Obtain specific types of benefits as a result of the program (new/retained jobs, environmental benefits, etc.)

- Foster an environment of product innovation

- Maximize effectiveness of ratepayer funds

- Install systems early in program period

Constraints might include:

- Available budget over the life of the program

- Uncertain budgets from year to year

- Limitations on the ability to transfer funds from one year to the next

- Limited program duration

- Limits on administration portion of budget

- The need to maintain consistency with an established incentive structure

\section{Purchasing Customer}

Next, consider possible goals and constraints from the purchasing customer's perspective.

Goals might include:

- Ensure that the system is "cost-effective""

- Improve the environment

- Offset total customer energy consumption using solar

Constraints might include:

- Limited borrowing power and/or access to financing to cover capital costs

\section{PV Industry}

Finally, consider possible goals and constraints from the perspective of the PV manufacturers and resellers.

Goals might include:

- Maximize short-term product sales

- Maximize product development (and thus long-term sales)

Constraints might include:

- Manufacturing capacity

- Limitations on the rate of company growth and/or access to capital

- Production costs

\footnotetext{
${ }^{9}$ Cost-effectiveness might be defined, for example, as a positive net present value over the life of the system, a payback in a specified number of years, or a minimum internal rate of return.
} 


\section{Incentive Structure Screening}

The screening step focuses on identifying major problems that may prevent a given structure from being implemented by a particular program. A starting point for the list of screening criteria is the list of goals and constraints developed above. Two screening examples are presented.

\section{Budgetary Example}

First, suppose that a utility has an incentive program funded through its public benefits charge and that the program is unable to carry over funds from one fiscal year to the next. Furthermore, suppose that the program has a fixed 10-year duration. Timing of expenditures is a critical constraint under this scenario and the various structures should be screened under this constraint.

Figure 6 presents hypothetical annual budget expenditures for a 10-year program that begins in 2007 and ends in 2017 and assumes a consistently growing stream of PV investments. The figure includes the annual expenditures for the EPBB, PBB, and four variant PBI structures. ${ }^{10}$

The figure suggests that the fixed duration PBI structures require payments that last 10 years after the end of the program for project awards made at the end of the program, ruling them out. The variable duration PBI structures meet the 10-year program constraint, but require budgets that are substantially increasing over time to pay for the cumulative number of projects throughout the life of the program (assuming additional projects are approved each year). In this case, only the EPBB or PBB structures appear to satisfy the program constraints - therefore these are the two programs that should be evaluated in more depth.

\footnotetext{
${ }^{10}$ While there is some difference in the present value expenditures for the various incentive structures due to differences in discount rates, the key point of the figure is the shape of the curves relative to each other.
} 


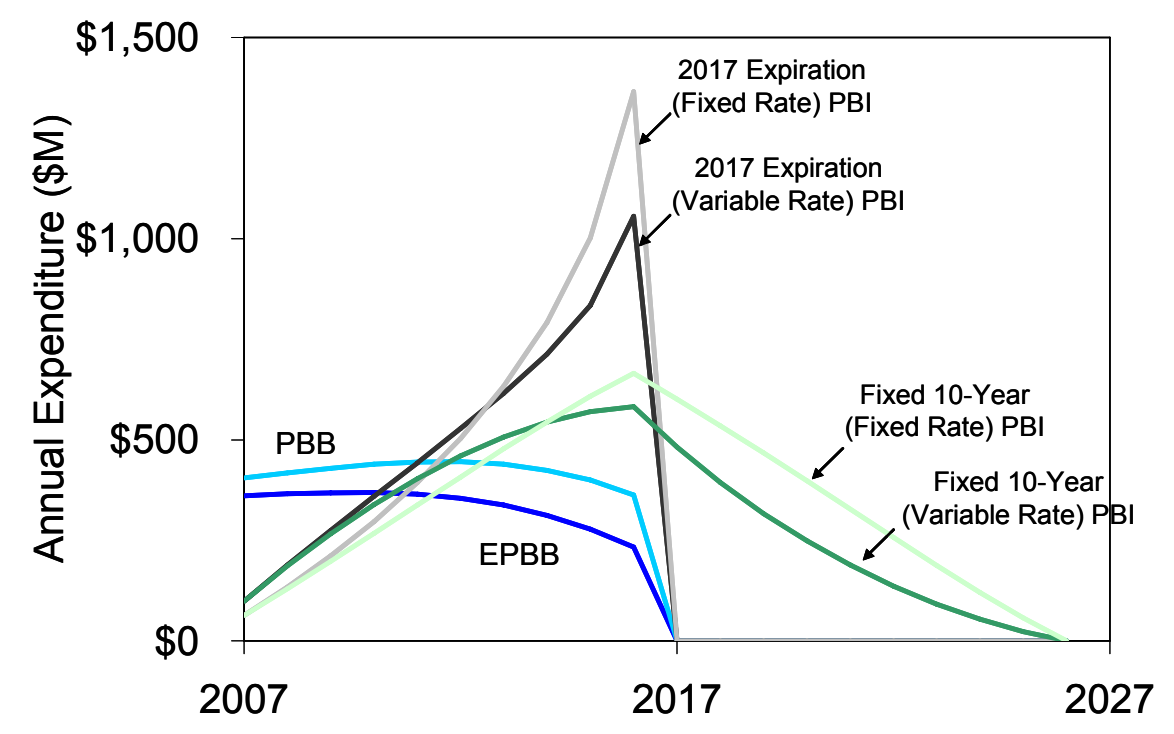

Figure 6. Annual budget expenditures for hypothetical program.

\section{Ratepayer Funds Example}

Next, suppose that a primary goal of a program is to maximize effectiveness of ratepayer funds. This rules out the capacity incentives (CBB and $\mathrm{CBI}$ ) because they do not hold the customer accountable for actual energy production. The EPBB, PBB, and PBI would be candidates for further analysis, because they encourage optimal system performance.

\section{Detailed Qualitative Evaluation}

A more rigorous qualitative analysis may be performed for the two or three incentive structures remaining from the screening step. Table 2 presents a set of attributes that program designers might consider at this stage. The table summarizes the relative strengths $(+)$ and weaknesses (-) for each of the five incentive structures.

The table identifies Program's Use of Ratepayer Money as being critical from the program's perspective. Each of these is subsequently divided into several subcategories. For example, the table divides the program's use of ratepayer funds into direct program cost, indirect program cost, and the assurance of energy production. Under each of these subcategories, the table also goes one level deeper to demonstrate that the direct program cost is a function of other criteria.

Consider a few examples of how the five incentive structures fare under specific criterion. First, consider how the incentive capitalizes on the agency's lower discount rate. In general, agencies and utilities have a lower cost of capital than consumers and businesses. As a result, structures that pay the incentive earlier in time (Buydowns) will cost the program less due to the difference in the time value of money for the agency/utility versus the consumer. Second, consider the criterion that protects against 
poor long-term system performance. This criterion encourages optimal system performance; the PBI structure excels in this area, because the incentive payments are directly linked to system output.

While there are many factors that are identified in this table, there may be others that the agency would develop for the qualitative assessment. The agency should choose the factors it feels are most relevant in providing it with an understanding of how to qualitatively evaluate the structures. 
Table 2. Qualitative assessment of attributes for various structures: Strength $(+)$, weakness $(-)$, depends $(+/-)$, and not determined (?).

\begin{tabular}{|c|c|c|c|c|c|}
\hline \multicolumn{5}{|l|}{ Program Perspective (Incentive Agency or Utility) } & PBI \\
\hline \multicolumn{6}{|l|}{ Program's Use of Ratepayer Money (\$ per $\mathrm{kWh})$} \\
\hline \multicolumn{6}{|l|}{ Direct Program Cost } \\
\hline Capitalizes on agency's lower discount rate & + & - & + & + & - \\
\hline Reduces production risk premium required by customers & + & + & + & - & - \\
\hline Promotes product innovation & - & - & $+/-$ & + & + \\
\hline Maximizes state and federal tax benefits & ? & $?$ & $?$ & $?$ & $?$ \\
\hline \multicolumn{6}{|l|}{ Indirect \& Administrative Cost } \\
\hline Minimizes number of payments to make to customer & + & - & + & $+/-$ & - \\
\hline Eliminates requirement of separate metering & + & + & + & - & - \\
\hline Reduces need to verify system performance for payment & + & + & $+/-$ & - & - \\
\hline Minimizes number of customer interactions ${ }^{11}$ & + & - & + & - & - \\
\hline \multicolumn{6}{|l|}{ Assurance of Energy Production } \\
\hline Protects against poor system design and installation & - & - & $+1-$ & + & + \\
\hline Protects against poor long-term system performance & - & - & - & $+/-^{12}$ & + \\
\hline \multicolumn{6}{|l|}{ Other Factors } \\
\hline $\begin{array}{l}\text { Smoothes annual expenditures when used w/o escrow } \\
\text { account }\end{array}$ & + & - & + & + & - \\
\hline Payments correspond to value being obtained over time & - & + & - & + & + \\
\hline Promotes systems that maximize hourly value to utility & + & + & + & + & - \\
\hline \multicolumn{6}{|l|}{ Industry Perspective (Manufacturer and System Reseller) } \\
\hline \multicolumn{6}{|l|}{ Product Sale } \\
\hline Promotes ease of sale & + & $+1-$ & + & $+1-$ & $+/-$ \\
\hline Represents transition from status quo & + & - & $+/-$ & - & - \\
\hline Reduces need for additional warranties & + & + & + & - & - \\
\hline \multicolumn{6}{|l|}{ Product Innovation } \\
\hline Rewards products $w /$ high $\mathrm{kWh}$ production per $\mathrm{kW}$ capacity & - & - & $+1-$ & + & + \\
\hline Rewards products (e.g. inverters) with long life times & - & - & - & + & + \\
\hline Lessens need to for agency to certify equipment & - & - & - & + & + \\
\hline \multicolumn{6}{|l|}{ Customer Perspective } \\
\hline \multicolumn{6}{|l|}{ Customer Economics } \\
\hline Minimizes payment risk & + & + & + & - & - \\
\hline Reduces initial capital/loan amount required by customer & + & - & + & + & - \\
\hline May improve long-term system performance & - & - & - & + & + \\
\hline Can be engineered to provide various cash flow streams & - & + & - & - & + \\
\hline
\end{tabular}

\footnotetext{
${ }^{11}$ Administrative cost is likely to be higher with PBI because there is likely to be more times where consumers are not paid due to non-performance.

12 There is a default risk associated with PBB where customers may have underperforming systems but the program may not be able to collect money back from customers due to non-performance.
} 


\section{PBI Example}

The following example illustrates how a utility with a clean energy program might combine the goals and constraints of the program from two perspectives (utility and customer), in a detailed qualitative analysis. Suppose that a utility wants to design a customer-owned PV incentive program that has the primary goal of maximizing PV energy production. The PBI structure is selected since it encourages optimal energy production.

The analysis begins with an examination of the perspectives of two key parties affected by the PBI structure: the utility that is making the incentive payments (and receiving part of the benefits of the PV system energy production) and the customer that is receiving the payments.

As shown in Figure 7, the utility uses a PBI to influence customer behavior: (i) the utility establishes the PBI structure (rate and duration), (ii) the customer determines whether or not to purchase, what sort of system to purchase, and how to install and maintain the PV system, and (iii) the utility obtains some of the benefits from the energy produced by the PV system.

Rate and duration of PBI (\$)

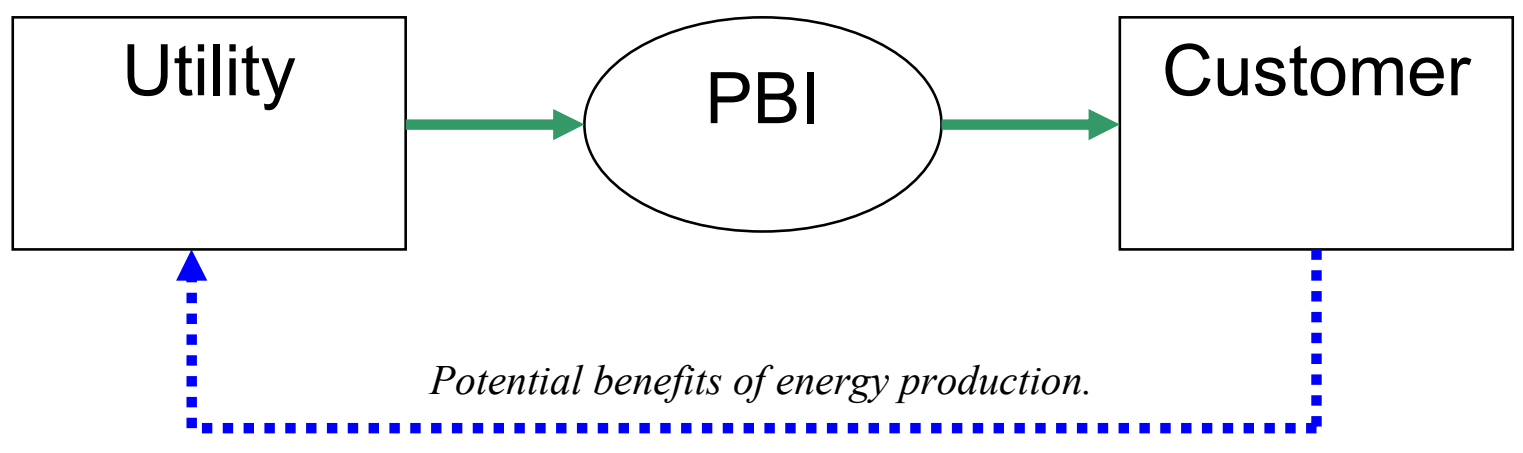

Figure 7. PBI structure establishes the interaction between utility and the customer.

There are two fundamental decisions that these parties face with regard to the incentive. First, the utility needs to establish the PBI structure. Second, the customer must decide whether (and when) to invest.

\section{Utility Perspective}

The value provided to the utility is a function of the PV system performance $(\mathrm{kWh})$ and the corresponding avoided utility costs of service, such as generation, transmission, and distribution. The added cost to the utility and its ratepayers includes the incentive payments plus administrative costs to run the program. 
The utility needs to establish a PBI structure that ensures that systems are installed and maintained in a way that most cost-effectively allocates ratepayer-collected funds. The utility seeks to maximize the benefits of its investment while keeping program spending within budget. In addition, the utility wants to be protected against funding systems that have poor performance (or no performance due to system failure, equipment removal, or some other reason) over the program duration.

A number of uncertainties affect the PV system's ultimate ability to deliver energy to the grid: timely installation, equipment ratings and efficiencies, orientation and shading, the solar resource at the customer's location, and ongoing maintenance practices. The PBI structure shifts the responsibility of all these factors to the customer-investor, and the utility's uncertainty is reduced to the quantity of energy production. This is illustrated by circles in Figure 8. The system could have good or poor performance for each year of the PBI program. If the system performs poorly in a given year, the PBI structure may need to be adjusted to stimulate new customers to properly maintain their systems in order to provide the desired amount of energy production.

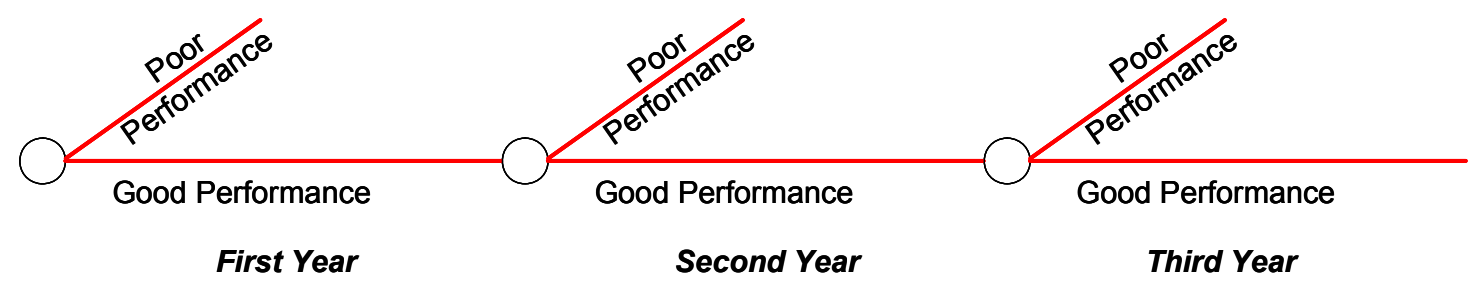

Figure 8. Utility perspective: PV system performance is a critical uncertainty.

\section{Customer Perspective}

In considering whether and when to invest in PV, the customer considers all of the economic benefits and costs, taking into account the continuing decline in PV system prices ${ }^{13}$ over time and the increase in utility rates over the same period of time. Benefits depend on the PBI structure, the utility rate structure, tax impacts, and system performance. Costs include capital and operation and maintenance costs.

Suppose that, from the customer's perspective, two basic criteria must be satisfied. First, the investment must be cost-effective. Second, as shown by the decisions represented by squares in Figure 9, the timing of the investment should result in the best economic advantage. The customer could invest in a given year or wait in anticipation of declining PV prices. Since the utility intends to maximize production using PV generators, the PBI should be designed to remove the benefit of waiting by offering a declining incentive rate commensurate with declining PV prices.

\footnotetext{
${ }^{13} \mathrm{PV}$ prices can have short-term increases when the demand for modules is high. While modeling efforts typically assume that prices decline over the long term, Appendix D presents an example of how an analysis should be applied if PV prices are increasing over the near term.
} 


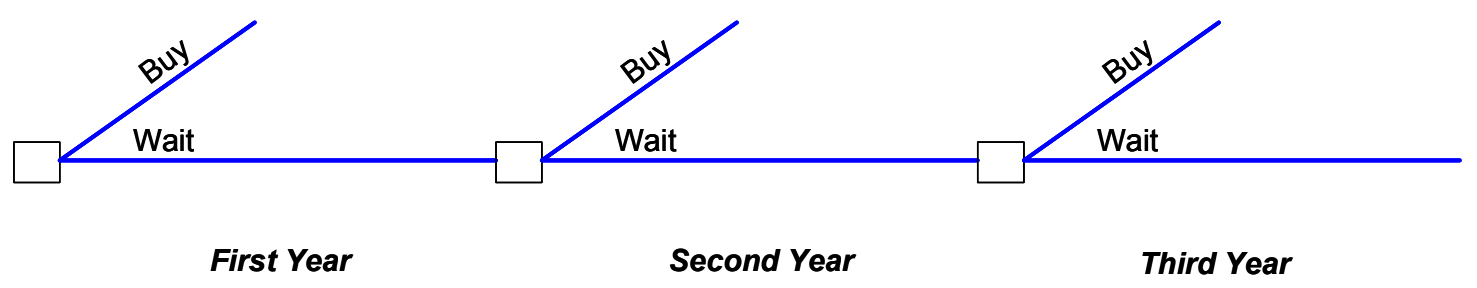

Figure 9. Customer perspective: Customer makes decision to buy now or to wait.

\section{Combined Perspectives}

The PBI structure flows out of the combined perspectives. The utility wants to create a PBI structure that provides customers with a sufficient incentive to invest sooner while protecting itself against poorly performing systems. It accomplishes this by combining the customer's investment decision with PV system performance uncertainty. Once the customer invests and the $\mathrm{PV}$ performs well, the utility pays the incentive. If, however, the system fails to perform as expected, the utility will make a reduced payment to the current customer. If the system fails altogether, this will leave the utility with a sufficient level of resources to provide future customers with an incentive program so that there will be more investment in PV. 


\section{Quantitative Evaluation Using Verification}

\section{Introduction}

The previous chapter's qualitative assessment is designed to screen out incentive structures that fail to satisfy critical program constraints and to qualitatively assess structures that best satisfy a program's goals. This chapter takes a more quantitative evaluation to achieve the same goals, which will be helpful to quantify the benefits and costs of particular incentive programs.

In order to conduct a quantitative analysis, PV output verification becomes critical. Each incentive structure, however, has an inherent level of verification that it is capable of providing. This section explores the inherent verification capabilities of the structures and examines how to conduct a quantitative evaluation for each. Appendix B provides the detailed analysis upon which this chapter is based.

\section{Performance Verification under Incentive Structures}

The U.S. PV industry is moving toward incentive structures that are tied to performance. Such structures, by verifying performance either through one-time power measurements or monthly energy metering, assure the granting agency and ratepayers that the PV systems are encouraged to perform as expected, that incentive funds are well spent, and that the agency or utility receives most, if not all of the expected cost savings.

The only structure that provides complete verification of energy production is a PBI that pays for as-delivered energy over the entire life ( 25 to 30 years) of the PV investment. Any incentive paid out over a shorter time period falls short of this ideal. All three capital buydown structures and any short-duration PBI structure (less than 25 or 30 years) fail to ensure complete verification.

While a long-term PBI represents the highest standard of verification and the best guarantee of performance, it comes with additional costs and requires long program durations. Meter reading, billing, and program administration costs all increase when verification requirements are more stringent over a longer period of time.

The agency therefore needs to consider the tradeoff between the benefits of verification (i.e., guaranteed energy production) versus the costs of implementation. It should also consider whether sufficient accuracy is provided by other structures (or a shorter PBI) with more limited verification by considering individual factors that account for longterm performance captured by the PBI. 


\section{Performance Factors}

An important observation from Appendix B is that the performance factors include both "one-time" design and installation decisions and "recurring" practices. Performance factors can be classified as follows: ${ }^{14}$

- One-Time Issues

○ System Rating (equipment ratings)

- Design Factor (orientation, shading)

- Location Factor (geographical location)

- Recurring Issues

- Availability Factor (dirt accumulation, increased shading from tree growth, module degradation, inverter failure, and maintenance)

$\circ$ Weather Factor (variation from typical year)

Incentive structures may be designed to include any or all of these performance factors, depending upon the desired level of verification and the implementation cost. For example, the CBB only includes the System Rating, while the PBI effectively includes all of the factors. These factors are described more fully below.

\section{System Rating}

System Rating $(\mathrm{kW})$ can account for equipment ratings and installation effects and may be expressed in either units of DC or AC. The CBB incentive structure defines incentive payments based on System Rating, typically without independent field verification.

An alternative is to use a system rating that can be verified based on field measurements. While most incentive structures have not been stated in system AC units and thus could not be verified in the field, nothing prevents the industry from using a system AC rating. See Appendix $\mathbf{C}$ for a more detailed discussion of the rating issue. As a result, all of the incentive structures have the potential to provide for system rating verification.

\section{Design Factor}

The Design Factor quantifies the effects of system design, including shading and system orientation (horizontal, tilted, tracking, etc.) or multiple system orientations if the PV array is split in various directions. It is defined as the ratio of two simulated outputs using a common weather data set representing the location of the system. The numerator uses actual design orientation and shading, while the denominator uses a reference system design at the same location.

Incentives that include a Design Factor will reward system installations that are oriented for optimal energy production and where shading does not adversely affect output. Such an incentive structure provides partial assurance of performance by promoting effective system designs.

\footnotetext{
${ }^{14}$ See Reference [14] for a slightly different categorization.
} 


\section{Location Factor}

The Location Factor quantifies the effect of geographical location. It is the ratio of two simulated system outputs based on long-term weather data. The numerator uses weather data from the actual location while the denominator uses data from a reference location. The Location Factor will promote installations at the most favorable locations in the region where the incentive is available.

\section{Availability Factor}

The Availability Factor captures the effects of system degradation and outages related to maintenance and equipment life. PV panels that are not regularly cleaned deliver reduced energy. Modules degrade naturally over time, which also results in reduced output. Inverter failures from damaged switching devices or blown fuses will prevent energy delivery until the problems are rectified. All of these long-term issues are reflected in the Availability Factor.

Availability Factor equals the ratio of two quantities based on the actual design and location. The numerator is based on measured production per unit of actual capacity while the denominator is based on simulated production per unit of reported capacity using the actual weather data that corresponds to the same time and location as the measured data.

Incentives that include the Availability Factor encourage proper maintenance practices, such as cleaning and repairs, to ensure ongoing production. It may also spur manufacturing innovation in developing products with long service lives.

\section{Weather Factor}

The Weather Factor establishes the difference between actual and ideal (long-term predicted) weather patterns. It equals the ratio of two quantities that are based on actual design and actual location. The numerator is based on actual weather data while the denominator is based on predicted long-term weather data. As long as realistic data is used to model long-term behavior, the Weather Factor represents the transfer of weather viability risk from the granting agency to the investor-owner. ${ }^{15}$

\section{Comparison of Various Structures}

The five incentive structures are compared in relation to the above performance factors in Table 3. The table indicates that all of the structures have the potential to provide for system rating verification (so long as they include some sort of field verification). The $\mathrm{EPBB}, \mathrm{PBB}$, and $\mathrm{PBI}$ structures can be designed to verify the one-time performance effects of system design and geographical location while the $\mathrm{CBB}$ and $\mathrm{CBI}$ structures cannot. The PBB and PBI structures may be designed to take into account the full range of performance factors and provide the highest assurance of energy delivery. Note that while some form of verification is possible for all incentive structures, this has not

\footnotetext{
${ }^{15}$ New York State Energy Research and Development Authority (NYSERDA) is one agency that has implemented a system that compares long-term average weather data to actual weather data using satellite data. This site is available at www.iedat.com/sirs-ny/sirs-ny.php3. This satellite data has been linked to the Clean Power Estimator so that New York PV system owners can verify their system performance.
} 
typically been done in practice because the focus has been on component-based ratings rather than system-based ratings. Component-based ratings are very difficult to verify after a system has been installed in the field.

Table 3. Ability of structures to account for factors that affect system performance.

\begin{tabular}{|l|l|c|c|c|c|c|}
\hline & Factor & CBB & CBI & EPBB & PBB & PBI \\
\hline One-Time & System Rating & $\mathrm{X}$ & $\mathrm{X}$ & $\mathrm{X}$ & $\mathrm{X}$ & $\mathrm{X}$ \\
\hline & Design & & & $\mathrm{X}$ & $\mathrm{X}$ & $\mathrm{X}$ \\
\hline & Location & & & $\mathrm{X}$ & $\mathrm{X}$ & $\mathrm{X}$ \\
\hline Recurring & Availability & & & & $\mathrm{X}$ & $\mathrm{X}$ \\
\hline & Weather & & & & $\mathrm{X}$ & $\mathrm{X}$ \\
\hline
\end{tabular}




\section{Incentive Design}

\section{Introduction}

The purpose of any PV incentive program is to provide a temporary pathway for investment until such time as prices decline to the point of cost-effectiveness in the marketplace ("market transformation"). The program therefore presumes a decline in prices that will follow from ongoing industry experience, increased volumes of production and other forces, in part driven by the incentives themselves. An effective incentive design, therefore, should take into account this anticipated price decline. This chapter describes two strategies for addressing this in incentive structure design.

One strategy is to design the incentive to meet a fixed cost-effectiveness test each year during the program. The incentive is intended to provide the necessary funding so that the consumer considers the investment to be cost-effective each year. In an environment of declining prices, the incentive rates would likewise decline and the program would neither encourage the consumer to invest early nor encourage the consumer to delay investment.

A second strategy is to establish an incentive that increases the relative cost-effectiveness over time, thus shaping market demand and encouraging an acceleration of participation. With such a program, designers would therefore expect that market penetration would increase over the duration of the program in relation to the increasing economic advantage to the consumer. While this approach would cause some consumers to wait in order to achieve better economic return, it is more closely tied to traditional market economics where the quantity of sales is related to the cost-effectiveness of the investment.

\section{Maintain Constant Cost-Effectiveness}

In the first strategy, the goal of incentive structure design is to make the PV investment equally cost effective today as in the future. Under such a structure, the customer has no advantage or disadvantage of delaying investment because the relative cost-effectiveness is held constant even though PV prices are declining. A detailed derivation of the mathematical formulas using this approach as applied to a PBI structure is presented in Appendix D.

The appendix demonstrates several things. First, a variable duration and variable rate PBI structure (refer back to Figure 3 for an illustration of the structure) would apply for all customers independent of when the investment is made. Second, the year-by-year incentive is decreasing over time (as PV prices decline and the level of incentive to make the system cost-effective declines as well). ${ }^{16}$ Third, the incentive rate is calculated based on the difference between the added cost of investing early (because one loses the benefit of declining prices) minus the additional utility bill savings of investing early (because one gains the benefit of obtaining utility bill savings earlier rather than later).

\footnotetext{
${ }^{16}$ See Appendix D for a discussion of the situation where prices are expected to increase.
} 


\section{Shape Market Demand}

The second strategy for dealing with declining PV prices is to design an incentive structure that is consistent with program goals and then to assess the reasonableness of the implied market demand. Under such a program, payments are not necessarily defined to meet cost-effectiveness. Economic return may increase over the duration of the program, leading to higher participation rates year by year according to market demand. A detailed derivation of the mathematical formulas using this approach is presented in Appendix E.

This is the approach that was used to help support the design of the California Energy Commission (CEC) New Solar Homes Partnership (NSHP) incentive [15]. Key points of that analysis are repeated here for the benefit of the reader and the results are summarized in Table 4. As explained below, increased economic return can still mean that the incentive level provided to consumers decreases over time, just not as rapidly as they would under the first strategy for dealing with declining PV prices.

The first column in Table 4 presents the incentive rate that is consistent with the following program goals:

- $400 \mathrm{MW}$ of PV installations

- \$2.25 per Watt starting incentive rate for smooth transition from Emerging Renewables Program (ERP) to the NSHP

- Declining incentives to zero by 2017

- $35 \%$ market growth rate

- $\$ 300$ Million incentive budget

The declining incentive level, which can be either calendar-based (Figure 10) or volumebased (Figure 11), is combined with other variables (rate structures, tax effects, etc.) to perform a cost-effectiveness test from the purchasing customer's perspective for each year of the analysis. Possible tests include simple payback, net present value, internal rate of return, and net cash flow. The first year net cash flow was used as part of the NSHP analysis and the results are presented in the third column of Table 4. The annual volume (second column of Table 4) is combined with the market size and average PV system size to determine the market sales (last column of Table 4).

The market sales are plotted versus the cost-effectiveness results in order to determine the implied market demand (Figure 12). The policy maker's job is to assess whether or not this implied market demand is realistic. If it is deemed to be unrealistic, then one or more of the program goals (MW goal, market growth rate, budget, or incentive structure) should be revised. 
Table 4. Proposed CEC new homes incentive structure.

\begin{tabular}{|l|cccc|}
\cline { 2 - 5 } \multicolumn{1}{c|}{} & $\begin{array}{c}\text { Incentive } \\
\left.\mathbf{( \$ \mathbf { ~ }}_{\text {AC-CEC }}\right)\end{array}$ & $\begin{array}{c}\text { Volume } \\
\left.\text { (MW }_{\text {AC-CEC }}\right)\end{array}$ & $\begin{array}{c}\text { Net Savings } \\
(\mathbf{\$} / \mathbf{k W h})\end{array}$ & Market Sales \\
\hline $\mathbf{2 0 0 7}$ & $\$ 2.25$ & 7 & $(\$ 0.02)$ & $3.1 \%$ \\
$\mathbf{2 0 0 8}$ & $\$ 2.03$ & 10 & $(\$ 0.01)$ & $3.9 \%$ \\
$\mathbf{2 0 0 9}$ & $\$ 1.80$ & 13 & $\$ 0.00$ & $5.0 \%$ \\
$\mathbf{2 0 1 0}$ & $\$ 1.58$ & 18 & $\$ 0.01$ & $6.5 \%$ \\
$\mathbf{2 0 1 1}$ & $\$ 1.35$ & 24 & $\$ 0.03$ & $8.3 \%$ \\
$\mathbf{2 0 1 2}$ & $\$ 1.13$ & 33 & $\$ 0.04$ & $10.7 \%$ \\
$\mathbf{2 0 1 3}$ & $\$ 0.90$ & 44 & $\$ 0.05$ & $13.8 \%$ \\
$\mathbf{2 0 1 4}$ & $\$ 0.68$ & 60 & $\$ 0.06$ & $17.7 \%$ \\
$\mathbf{2 0 1 5}$ & $\$ 0.45$ & 81 & $\$ 0.07$ & $22.8 \%$ \\
$\mathbf{2 0 1 6}$ & $\$ 0.23$ & 109 & $\$ 0.08$ & $29.3 \%$ \\
\hline
\end{tabular}

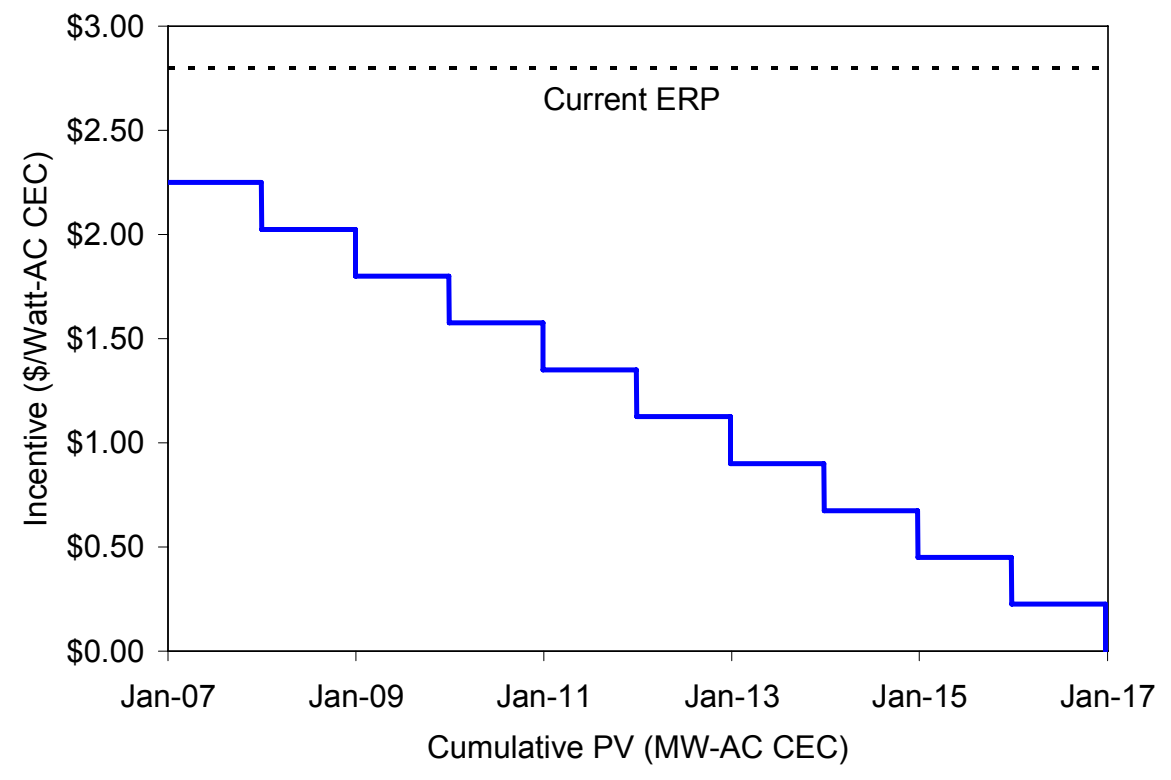

Figure 10. Incentive level using calendar-based trigger. 


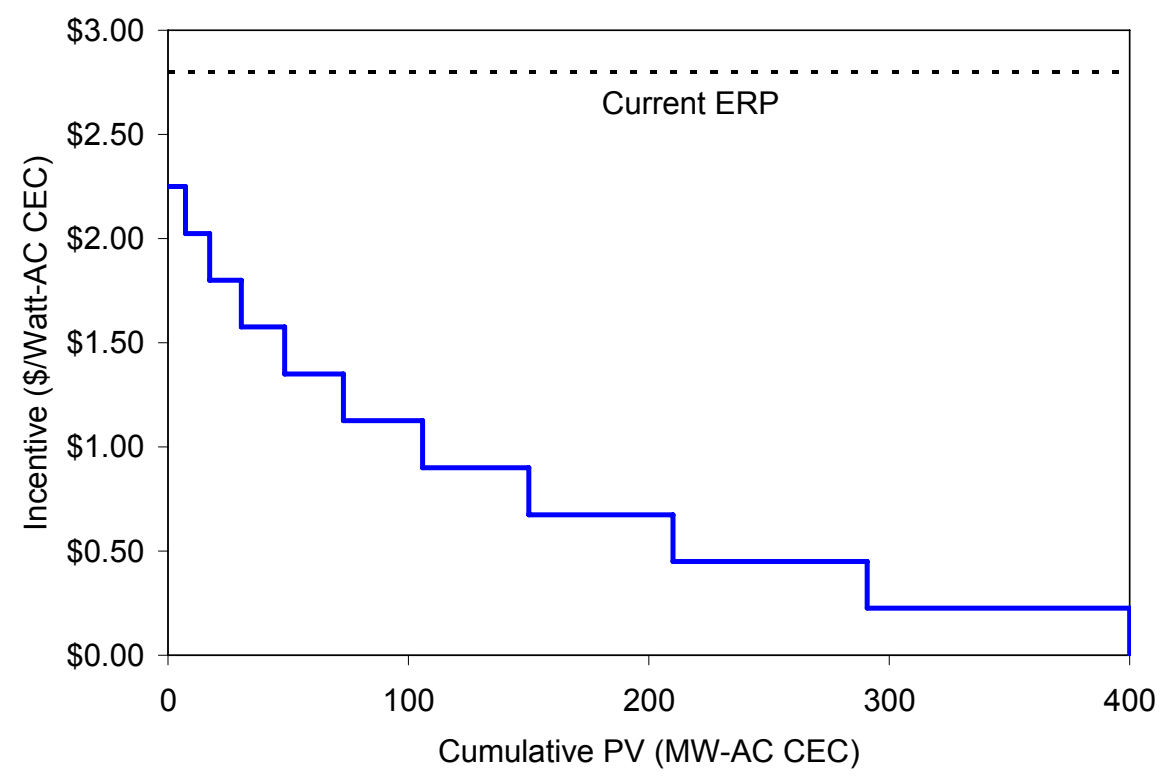

Figure 11. Incentive level using volume-based trigger.

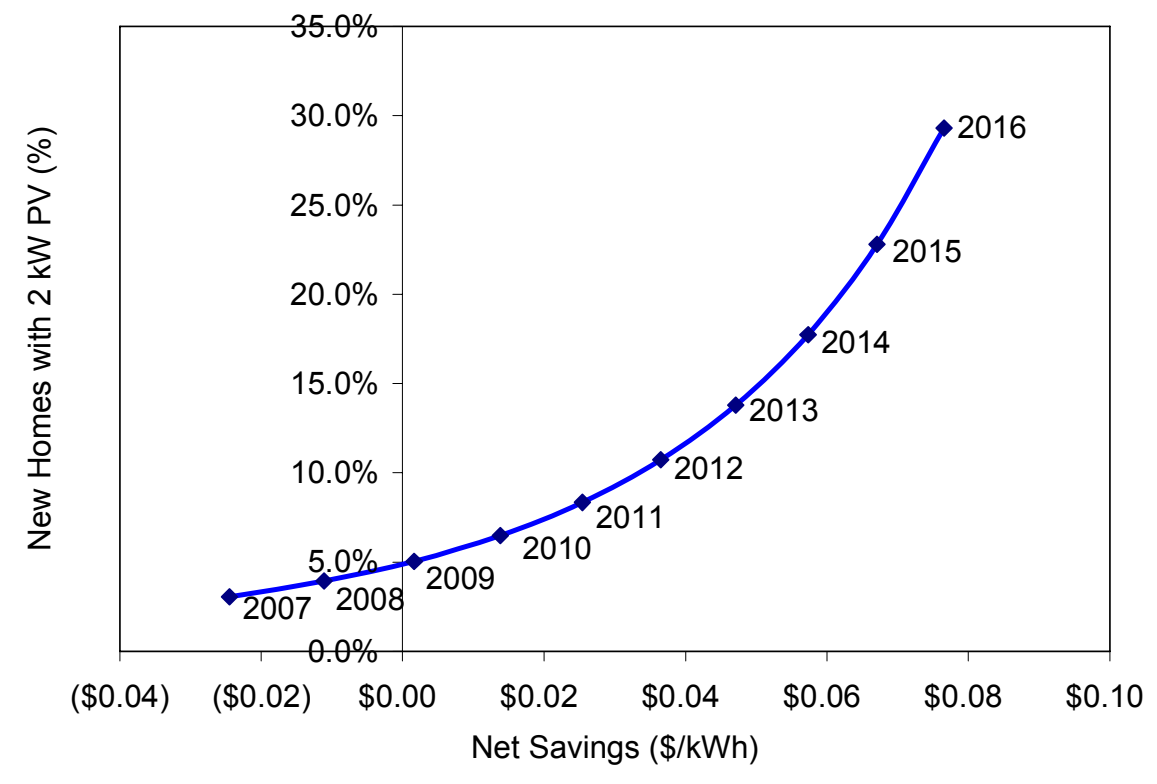

Figure 12. Implied market demand. 


\section{Program Administration and Other Factors}

The incentive program needs to be implemented once the incentive structure has been selected and designed. Program implementation is a broad topic that goes well beyond the scope of this study. It is useful, however, to discuss a few key areas as they directly apply to incentive design. This chapter discusses some issues related to program administration and other factors that relate to incentive design.

\section{Administrative Tools}

One issue that deserves consideration is the software tool(s) that will be used to manage the program. There are basically two options that are available. The first option is to internally develop tools using spreadsheet or database software. The second option is to use software programs that have been developed specifically for clean energy program management.

When evaluating the costs and benefits of the various alternatives, consideration should be given to all aspects of program management. Building an internal software tool will require resources (time and money) to develop, whereas buying software will cost money to purchase and may require training. Implementation concerns include assessing the costs of incentive application processing, internal reporting, external reporting, program analysis, and program management after systems have been installed (including the analysis of verified system performance). The broader data collection requirements of the program (including model validation and system output recording) should also be given consideration in making the decision.

\section{Incentive Trigger}

Another administrative issue is what event will trigger a change in the incentive rate. Two methods that have been proposed are calendar-based and volume-based triggers. A calendar-based trigger means that the rate changes on a specific, pre-determined date. A volume-based trigger means that the rate changes at the point in time when a specific volume target has been reached.

Appendix E shows that when the market is growing at an exponential rate and the incentive rate decreases linearly each year, the following results are true:

- The incentive trigger mechanism can be either calendar-based or volume-based.

- A calendar-based trigger results in greater certainty as to how long the program will last.

- A volume-based trigger results in greater certainty as to the amount of PV that will ultimately be installed under the program and the total cost of the program. 


\section{Incentive Calculation}

Another administrative issue is how to calculate the incentive payment.

- $\mathrm{CBB}$ or CBI payments are based on equipment capacity. To date, most U.S. incentive programs reference the equipment listed by the CEC to perform these calculations. $^{17}$

- PBI payments are based on measured system performance. While measured system performance does not rely on simulation models or verified equipment to make the payment, it is likely that the agency will need to perform an expected incentive payment calculation in order to properly budget the program and to manage funds and cash flow.

- EPBB payments are based on estimated system performance as determined by modeling and possibly field verification procedures.

- $\quad$ PBB payments are based on estimated system performance with a true up occurring after the system begins operation based on actual, measured system performance.

\section{EPBB Calculation}

Several issues need to be addressed for the EPBB incentive calculation: (a) which models will be used to estimate the performance, (b) which performance attributes will be estimated and (c) which attributes will be verified by measurement.

For estimating performance, two internet-accessible models are available: PVWATTS ${ }^{18}$ and Clean Power Estimator. ${ }^{19}$ If the design incorporates shading into the analysis, PVWATTS will need to be combined with the output from a Solar Pathfinder ${ }^{20}$ analysis or some other shading analysis; Clean Power Estimator has an integrated shading analysis. ${ }^{21}$ A third model is currently under development by the California Energy Commission [16].

Once the model is chosen, the formula that will be used to perform the calculation must be selected. Appendix B demonstrates that the PBI calculation could be expressed in either of two mathematically equivalent ways for the purpose of incentive structure comparison. Similarly, the EPBB calculation can be expressed in two mathematically equivalent ways. They include:

- Incentive Energy Rate $(\$ / \mathrm{kWh}) \mathrm{x}$ Expected Output (kWh)

- Incentive Capacity Rate $(\$ / \mathrm{kW})$ x System Capacity $(\mathrm{kW})$ x Design Factor $(\%)$

Appendix B suggests that, while multiplying an energy rate by expected output is more intuitive, the second method is analytically superior because it reduces the incentive

\footnotetext{
${ }^{17}$ www.consumerenergycenter.org/erprebate/equipment.html.

${ }^{18} \mathrm{http}: / /$ rredc.nrel.gov/solar/codes_algs/PVWATTS

${ }^{19} \mathrm{http}: / /$ www.clean-power.com.

${ }^{20} \mathrm{http}: / / \mathrm{www}$.solarpathfinder.com.

${ }^{21}$ Clean Power Estimator has also been integrated into PowerClerk (www.powerclerk.com) to automatically perform the necessary EPBB calculations. PVWatts has been used to calculate the EPBB for a variety of programs.
} 
payment's sensitivity to data and modeling inaccuracies, and incorporates the system's rating.

\section{Issues Not Given Detailed Consideration}

A number of issues were not given detailed consideration in this report. They are listed below.

\section{Billing and Administrative Costs}

Billing and administrative costs associated with running an incentive program under different incentive structures have not been given detailed consideration in this report. The agency should consider the costs to implement the various programs, including onetime setup costs, incremental per-customer costs, and the costs of integrating a payment mechanism into the existing utility billing system.

\section{Net Metering}

Net metering is currently offered in over 35 states, usually to customers of investorowned utilities. Net metering, establishes retail value for production during all hours, even when wholesale electricity rates are lower. This Handbook considered net metering as part of the utility bill savings available from PV systems.

\section{Green Tag Ownership}

Some states mandate that utilities procure a percentage of energy from renewable energy sources under a "renewable portfolio standard (RPS)," while some utilities procure renewables on a voluntary basis to claim the environmental attributes. In either case, PV installations have value to utilities by either fulfilling RPS requirements or contributing to environmental goals. Three regions (New England, the Pennsylvania-New JerseyMaryland interconnect, and Texas) currently track renewable energy certificates and three other regions (New York, the West and the Mid-West) are currently constructing green tag tracking systems. In these systems, the renewable attributes of PV may be certified, a single owner of the attribute must be identified and the owner of the "green tag" may sell it in various markets, either in-state or out-of-state. This Handbook did not address this issue of Green Tag Ownership. 


\section{Conclusions and Future Work}

\section{Summary}

This Handbook was designed for agencies and utilities that operate or intend to operate incentive programs for customer-owned PV systems. Its purpose is to help these agencies select and implement an incentive design that best meets the needs of their program. The Handbook began with a discussion of the various incentive structures that are available and then provided qualitative and quantitative methods to select and then design the most appropriate structure given programmatic goals and constraints. It concluded with some considerations related to program administration.

\section{Conclusions}

Based on the goal of focusing on structures that promote optimal performance, two structures emerge as being particularly attractive. One is a PBI and the other is an EPBB. A PBI makes multiple payments over a longer period of time, based on actual, measured energy production by the system. An EPBB makes a single upfront payment based on expected system performance.

Both a PBI and an EPBB can address one-time issues that have the potential to affect system output. These one-time issues include system rating (based on equipment and installation), system design (based on orientation, shading), and geographical location. Each of these structures, however, has strengths and weaknesses.

PBI exceeds EPBB's ability to guarantee energy production because it captures the effect of recurring issues, such as dirt accumulation, module degradation, and inverter failure as well as year-to-year weather variations. The PBI, however, is likely to have higher administrative costs due to its longer duration and it does not address the initial capital investment barrier as well as the EPBB.

The EPBB exceeds the PBI's ability to address the initial capital investment barrier without relying on external financial resources and it is likely to have simpler program administration. Unlike the PBI, however, the EPBB cannot guarantee long-term system output because it can only address one-time performance factors.

A clean energy program's selection of the incentive structure will depend upon the program's goals, constraints, and beliefs about where the potential performance problems will occur and program administration costs. Depending upon the size of the program, it may be desirable for a program to implement multiple structures simultaneously.

\section{Next Steps}

There are several issues that should be addressed in future work to make the results of this Handbook more useful.

First, this Handbook embodies a substantial level of modeling. The models should be verified using incentive program data. This can be accomplished by carefully designing 
and incorporating data collection efforts into the incentive processing system. Verification should include the cost-effectiveness tests used by consumers to make investment decisions, implied market demand associated with these cost-effectiveness tests, and PV price projection models within the context of world demand. In addition, programs should collect a sufficient level of field data (verified $\mathrm{kW}$ and $\mathrm{kWh}$ ) to numerically address the issue of which portions of the PV system (equipment, design, and operation) are most likely to affect long-term system performance.

Second, this Handbook evaluated incentive structures of increasing verification levels, up to and including the PBI. The next generation incentive structure may be a value-based (or an expected-value based) incentive [16]. This structure would pay based on the timeand location-specific value of the output rather than on single rate per $\mathrm{kWh}$. For example, PV systems that are oriented to maximize production during high demand, or systems that are located in transmission-constrained areas could be eligible for higher incentive amounts. This structure has analytical appeal since it would provide the highest cost savings to the utility. Prior to implementation, however, the incentive program should perform a PV value analysis to determine if the added computational and implementation complexity of implementing a value-based incentive justifies the added benefit. $^{22}$

Third, it may be useful to create an electronic screening tool to assist in incentive program design. The tool would cover both the qualitative aspects (by asking the user questions about their priorities) and the quantitative aspects of incentive design.

Fourth, further consideration could be given to how to expand the analysis to include other perspectives such as non-participating ratepayers, local, state, and federal government, and the PV industry. While some consideration was given to this area, it would be beneficial to expand these efforts [4].

\footnotetext{
${ }^{22}$ An example of a recent value analysis is one that was performed for Austin Energy [11]. That study considered five fixed configurations (horizontal, South- $30^{\circ}, \mathrm{SW}-30^{\circ}$, West- $30^{\circ}$, West- $45^{\circ}$ ) and two 1-axis tracking configurations (horizontal and $30^{\circ}$ tilted). It found that the per $\mathrm{kWh}$ value ranged by plus or minus 5 percent depending upon system configuration.
} 


\section{References}

[1]. Robert M. Margolis, "Photovoltaic Technology Experience Curves and Markets," Paper Presented at the NCPV and Solar Program Review Meeting, Denver Colorado, March 24, 2003.

[2]. Thomas E. Hoff and Robert M. Margolis, "Economic Benefits of PerformanceBased Incentives," Working Paper, July 9, 2004, www.clean-power.com.

[3]. Thomas J. Starrs, "Designing a Performance-Based Incentive for Photovoltaic Markets," American Solar Energy Society’s Solar 2004 Conference, Portland, OR, July 2004.

[4]. Thomas E. Hoff and Robert M. Margolis, "Moving Toward a More Comprehensive Framework to Evaluate Distributed Photovoltaics," Internal NREL Report, June 2005, http://www.clean-power.com/research/customerPV/EvaluationFramework.pdf.

[5]. Kelly Sackheim, "Photovoltaic Performance Based Incentives Program

Development,",Final Report, SMUD RFP No. 40512.CJB, September 21, 2005.

[6]. "Motion of the Americans for Solar Power for Adoption of Performance-Based Incentives for Large Commercial Customers in the California Solar Initiative," November 10, 2005.

[7]. Nellie Tong, "Emerging Renewables Program Systems Verification Report 20042005," December 2005.

[8]. Commissioner Peevey and ALJ Malcolm, "Interim Order Adopting Policies and Funding for the California Solar Initiative," January 12, 2006, www.cpuc.ca.gov/word_pdf/AGENDA_DECISION/52719.pdf

[9]. California Public Utilities Performance Based Solar Incentives Workshop, March 16, 2006, http://www.cpuc.ca.gov/static/energy/solar/060316 pbiworkshop.htm

[10]. Thomas E. Hoff, "Overview of PBI Design Issues," Presented at the California Public Utilities Performance Based Solar Incentives Workshop on March 16, 2006, http://www.clean-power.com/research/customerPV/CPUC PBI_Workshop.pdf and http://www.cpuc.ca.gov/static/energy/solar/060316_pbipresentations.htm.

[11]. Thomas E. Hoff, et. al., "The Value of Distributed Photovoltaics to Austin Energy and the City of Austin," March 17, 2006, http://www.austinenergy.com/About\%20Us/Newsroom/Reports/PV-ValueReport.pdf

[12]. "CPUC Energy Division Staff Proposal for California Solar Initiative Design and Administration 2007-2016, Rulemaking 06-03-004 (Filed March 2, 2006)," April 24, 2006, http://www.cpuc.ca.gov/PUBLISHED/RULINGS/55786.htm. 
[13]. "Comments of the California Solar Energy Industries Association, PV Now, and the Vote Solar Initiative Regarding the CPUC Energy Division Staff Proposal for California Solar Initiative Design and Administration 2007-2016," May 16, 2006, http://www.cpuc.ca.gov/static/energy/solar/comments $\% 20 \mathrm{ca} \% 20$ solar $\% 20 \mathrm{ind} \% 20(\mathrm{x} 7780$ 1).pdf.

[14]. Tim Tutt, "New Solar Homes Partnership," June 12, 2006, http://www.energy.ca.gov/renewables/06-NSHP-1/documents/2006-0612_workshop/2006-06-12 TUTT_TIM_OVERVIEW.PDF.

[15]. Thomas E. Hoff, Ryan Wiser, and Mark Bolinger, "Incentive Level Analysis," June 12, 2006, http://www.energy.ca.gov/renewables/06-NSHP-1/documents/2006-0612 _workshop/2006-06-12_CLEAN_POWER INCENTIVE.PDF.

[16]. Bill Pennington, "Technical Procedures, Eligible Systems and Specifications, Expected Performance-Based Incentives," June 12, 2006, http://www.energy.ca.gov/renewables/06-NSHP-1/documents/2006-0612 _workshop/2006-06-12_PENNINGTON_BILL.PDF.

[17]. Galen Barbose, Ryan Wiser, and Mark Bolinger, "Designing PV Incentive Programs to Promote Performance: A Review of Current Practice," Draft Report, August 2006. 


\section{Appendix A: Performance-Based Elements in PV Incentive and REC Programs ${ }^{23}$}

\section{Introduction}

There is a wide range of performance-based approaches and program durations currently used across the U.S. As shown in Table 5, there are four main types of incentive programs: (1) state incentive programs, (2) Renewable Energy Credit (REC) purchase programs developed for compliance with renewable portfolio standards, (3) voluntary green power programs, and (4) utility PV incentive programs. Each program is described in more detail in the subsections below.

\section{State PV Performance Incentive Programs}

States are showing increased interest in implementing a performance-based approach to PV incentive programs to ensure quality installations that operate well. Performancebased approaches typically involve either payments over time based on direct metering (PBI) or upfront payments based on expected performance using production estimation software, shading analysis and other site-specific details (EPBB). The list below highlights some of the state PV performance incentive programs described in Table 5.

- The Pennsylvania Sustainable Development Fund (SDF)'s PV program mixes a $\$ 4 / \mathrm{W}$ rebate with a one-time PBI of $\$ 1 / \mathrm{kWh}$ for the first year's generation. Unique among incentive programs, SDF also offers installers a PBI of $\$ 0.10 / \mathrm{kWh}$ for the first year's production. (Note: this program is currently closed.)

- The Emerging Renewables Rebate Program in California offers an option for consumers to participate in a PBI pilot program, paying out $50 \phi / \mathrm{kWh}$ for three years in lieu of the traditional $\$ / \mathrm{kW}$ buydown - currently at $\$ 2.60 / \mathrm{kW}$ for PV.

- Wisconsin offers an EPBB calculated using the PVWATTS production estimate that incorporates shading and other site-specific conditions. The incentive is paid after installation similar to capacity-based rebates.

- Connecticut recently transitioned its previous capacity-based program to an EPBB structure calculated using Clean Power Estimator through PowerClerk.

- In 2005, Washington State enacted a long-term PBI of $\$ 0.15 / \mathrm{kWh}$ (capped at $\$ 2,000$ per year) through June 30,2014 , for individuals, businesses, or local governments that generate electricity from PV and other renewables. Using a set of multipliers, an even greater incentive is paid if the modules, inverter, or other components are manufactured in Washington State. The state's utilities, whose participation is voluntary, will pay the incentives and earn a tax credit equal to the cost of those payments.

\footnotetext{
${ }^{23}$ This appendix was assembled by Sue Gouchoe, North Carolina Solar Center.
} 
Table 5. Performance-based elements in PV incentive and REC programs.

\begin{tabular}{|c|c|c|c|}
\hline State & Program Name & Amount & Payment Duration \\
\hline \multicolumn{4}{|c|}{ State PV Incentive Programs } \\
\hline California & $\begin{array}{l}\text { CEC Emerging Renewables Program } \\
\text { PBI Pilot }\end{array}$ & $\$ 0.50 / \mathrm{kWh}$ & 3 years \\
\hline Pennsylvania & $\begin{array}{l}\text { Sustainable Development Fund Solar } \\
\text { PV Grant Program }\end{array}$ & $\begin{array}{l}\$ 4 / \mathrm{W} \text { capacity-based incentive plus } \\
\$ 1 / \mathrm{kWh} \text { produced in first year }\end{array}$ & 1 year \\
\hline Washington & $\begin{array}{l}\text { Renewable Energy Production } \\
\text { Incentives }\end{array}$ & $\begin{array}{l}\$ 0.15 / \mathrm{kWh} \text {, multiplied by a factor } \\
\text { dependent on technology type and } \\
\text { where equipment was manufactured }\end{array}$ & Through mid-2014 \\
\hline Wisconsin & Focus on Energy Incentives/Grants & $\begin{array}{l}\$ 1.00-\$ 2.00 / \mathrm{kWh} \text { depending on } \\
\text { installer and building type; } \\
\$ 1.50 / \mathrm{kWh} \text { for systems }>20 \mathrm{~kW}\end{array}$ & Upfront (EPBB) \\
\hline Connecticut & Clean Energy Fund Small PV Rebate & $\begin{array}{l}\$ 5,165 / \mathrm{W}-\mathrm{AC}, \text { adjusted based on } \\
\text { expected performance }\end{array}$ & Upfront (EPBB) \\
\hline \multicolumn{4}{|c|}{ REC Programs for RPS Compliance } \\
\hline Nevada & Renewable Energy Credit Program & Market based & undefined \\
\hline New Jersey & $\begin{array}{l}\text { Solar Renewable Energy Certificate } \\
\text { Program }\end{array}$ & $\begin{array}{l}\text { Market based; \$200 per MWh } \\
(\$ 0.20 \text { per } \mathrm{kWh})\end{array}$ & undefined \\
\hline New Mexico & PNM Customer Solar PV Program & $\$ 0.13 / \mathrm{kWh}$ & Through 2018 \\
\hline Arizona & SRP EarthWise Solar Energy Program & $\begin{array}{l}\$ 2.50 / \mathrm{W}-\mathrm{DC} \text {, adjusted based on } \\
\text { expected performance }\end{array}$ & Upfront (EPBB) \\
\hline \multicolumn{4}{|c|}{ Green Power Programs } \\
\hline Massachusetts & $\begin{array}{l}\text { Mass Energy } \\
\text { REC Incentive Program }\end{array}$ & $\$ 0.06 / \mathrm{kWh}$ & 3 years \\
\hline North Carolina & $\begin{array}{l}\text { NC GreenPower } \\
\text { Production Incentive }\end{array}$ & $\$ 0.18 / \mathrm{kWh}+$ avoided cost & Undefined \\
\hline Pennsylvania & $\begin{array}{l}\text { The Energy Cooperative } \\
\text { Solar Energy Buy-Back Program }\end{array}$ & $\begin{array}{l}\$ 0.28 / \mathrm{kWh} \text { for ECAP customers } \\
\$ 0.10 / \mathrm{kWh} \text { for PECO customers }\end{array}$ & 2 years \\
\hline $\begin{array}{l}\text { Tennessee } \\
\text { Kentucky } \\
\text { Georgia } \\
\text { Mississippi } \\
\text { North Carolina }\end{array}$ & $\begin{array}{l}\text { TVA } \\
\text { Green Power Switch Generation } \\
\text { Partners Program }\end{array}$ & $\begin{array}{l}\$ 500 \text { (residential only) plus } \\
\$ 0.15 / \mathrm{kWh} \text { (residential/small- } \\
\text { commercial) or } \$ 0.20 / \mathrm{kWh} \\
\text { (commercial) }\end{array}$ & 10 years \\
\hline $\begin{array}{l}\text { Washington } \\
\text { Oregon }\end{array}$ & $\begin{array}{l}\text { Bonneville Environmental Foundation } \\
\text { Solar Starters - REC purchase }\end{array}$ & $\$ 0.10 / \mathrm{kWh}$ & 5 years \\
\hline Washington & $\begin{array}{l}\text { Chelan County PUD } \\
\text { SNAP Program }\end{array}$ & $\$ 0.47 / \mathrm{kWh}+$ avoided cost & Undefined \\
\hline Wisconsin & $\begin{array}{l}\text { We Energies - } \\
\text { Solar Buy-Back Rate }\end{array}$ & $\$ 0.225 / \mathrm{kWh}$ & 10 years \\
\hline \multicolumn{4}{|c|}{ Utility PV Incentive Programs } \\
\hline Arizona & SRP Earthwise Solar PV Program & $\begin{array}{l}\$ 3.25 / \mathrm{W}-\mathrm{AC} \text { (commercial), adjusted } \\
\text { for performance \& system rating }\end{array}$ & Upfront (EPBB) \\
\hline California & SMUD Solar PV Program & $\begin{array}{l}\$ 2.80 / \mathrm{W}-\mathrm{AC} \text { (residential), } \$ 3 / \mathrm{W}-\mathrm{AC} \\
\text { (commercial), adjusted for expected } \\
\text { performance }\end{array}$ & Upfront (EPBB) \\
\hline California & LADWP Solar PV Program & $\begin{array}{l}\$ 0.04 / \mathrm{kWh}-\$ 0.16 / \mathrm{kWh} \text { depending } \\
\text { on system size, customer type, etc. }\end{array}$ & $\begin{array}{l}\text { Upfront (EPBB } \\
\text { based on } 20 \text { yrs. of } \\
\text { production) }\end{array}$ \\
\hline
\end{tabular}


Nearly all state PV programs, whether capacity-based or performance-based, allow the project owner to retain ownership of the renewable energy certificates (RECs) ${ }^{24}$ and to sell them separately. For example, PV owners in Washington State can combine the state production incentive with the REC purchase program offered by Bonneville Environmental Foundation, which provides two separate revenue sources. In New Jersey, participants in the state rebate program can sell their RECs via an online trading system to energy providers who must comply with the solar set-aside in the state's renewables portfolio standard (RPS). The New Jersey solar REC price is market based and therefore will fluctuate based on market conditions; currently NJ solar RECs are selling around \$265/MWh according to Evolution Markets. ${ }^{25}$

\section{Utility Compliance with RPS Solar Set-asides}

A growing number of state RPS programs contain provisions which require energy suppliers to provide specific percentages of retail energy from solar electric resources. Programs are still under development in some states, but the following utility and statewide performance-based programs have emerged. State solar RPS information was taken from the Database of State Incentives for Renewable Energy (www.dsireusa.org).

- The New Jersey RPS calls for at least $2.12 \%$ of retail sales (about 1,500 MW of PV capacity) to be met with solar electric generation by 2021. To demonstrate compliance with the solar set-aside, electric suppliers must use an on-line solar REC tracking system established by the NJ Board of Public Utilities. PV system owners register with the program and use the online market to sell S-RECs (in 1 megawatt-hour denominations). The S-REC program is anticipated to compensate system owners an average rate of around $\$ 200$ per MWh $(\$ 0.20$ per $\mathrm{kWh}$ ). An engineering estimate is used to calculate the monthly S-REC generation for systems under 10 kilowatts. The program web site allows owners of systems $10 \mathrm{~kW}$ and larger to upload monthly meter readings and/or production information.

- Nevada also has a 5\% solar set-aside by 2015 as part of its RPS. Each kWh of electricity generated from customer-maintained PV systems is equivalent to 2.4 RECs for RPS compliance purposes. Therefore, the solar set-aside will result in the equivalent of approx. $600 \mathrm{MW}$ of PV capacity or approx. $600 \mathrm{MW}$ of concentrated solar power; most likely it will be some combination of the two technologies. The two investor-owned utilities offer a capacity-based rebate for PV systems up to $30 \mathrm{~kW}$ and retain ownership of the RECs for RPS compliance. However, larger PV and other renewable energy installations register through the Nevada Public Utilities Commission and can sell RECs on a performance-basis. The REC price is market-based.

\footnotetext{
${ }^{24}$ Renewable energy certificates are a tradable commodity that capture the environmental attributes of electricity generated by a renewable facility and allow it to be traded separately from the energy. They may also be called RECs, tradable renewable credits (TRCs), green tags, attributes, or environmental attributes.

${ }^{25}$ Evolution Markets REC Monthly Market Update, June 2006, http://www.evomarkets.com/assets/mmu/mmu_rec jun_06.pdf
} 
- PNM, an investor-owned utility in New Mexico, offers a PBI program as part of its plan to comply with the state's RPS. PNM purchases RECs from customers who install solar PV systems (up to $10 \mathrm{~kW}$ ) at a rate of $\$ 0.13 / \mathrm{kWh}$ through 2018. The electricity output of the PV system may be used on-site, and customers retain their net-metering benefit.

\section{Green Power Programs}

In order to include solar in their green power product mix, several utilities and green tag marketers offer production-based incentives for PV energy and their associated RECs, or for REC-only transaction. The payments range from $\$ 0.06 / \mathrm{kWh}$ to $\$ 0.47 / \mathrm{kWh}$ with contract periods ranging from two years to 10 years. Some programs have not defined the payment duration.

- The Tennessee Valley Authority and participating distributors in Georgia, Kentucky, Alabama, Tennessee, North Carolina, Mississippi, and Virginia offer a $\$ 0.15 / \mathrm{kWh}$ incentive for a minimum of 10 years for PV or wind power (plus a one-time $\$ 500$ incentive to residents). Large commercial customers receive $\$ 0.20 / \mathrm{kWh}$ for 10 years. The output from these systems serves as renewable resources for TVA's Green Power Switch Program.

- We Energies offers to purchase electricity and associated RECs generated by PV systems owned by its Wisconsin customers to supply a portion of the energy sold under the "Energy for Tomorrow" green power program. The payment is $\$ 0.225 / \mathrm{kWh}$ for a 10 -year period.

- Chelan PUD (WA) offers up to $\$ 1.50 / \mathrm{kWh}$ plus an avoided cost payment for the combined RECs and electricity produced by PV and other renewables as part of the Sustainable Natural Alternative Power (SNAP) Program, the utility's green power program. The 2005 rate was $\$ 0.47 / \mathrm{kWh}$. Under the SNAP program, the PV system owner sells 100 percent of the PV generation. Payments are made to SNAP Producers annually, with the actual incentive rate based on the total amount contributed by Chelan customers to the SNAP program and the total $\mathrm{kWh}$ generated by SNAP producers. The duration of incentive payments is undefined. Several utilities in Minnesota and one in Alaska offer similar programs.

- NC GreenPower, a statewide green-power program in North Carolina, offers REC payments for grid-tied PV and other renewables. PV systems less than $10 \mathrm{~kW}$ generally receive $\$ 0.18 / \mathrm{kWh}$ for RECs plus approximately $\$ 0.04 / \mathrm{kWh}$ under a power-purchase agreement for the electricity value. The time period is undefined.

- The Bonneville Environmental Foundation, a nonprofit Green Tag marketer based in Portland, Oregon, has teamed with the Northwest Solar Cooperative to market RECs from small solar installations throughout Oregon and Washington. The cooperative pays PV system owners $\$ 0.10 / \mathrm{kWh}$ for a 5-year contract period for RECs. BEF offers the Green Tags for resale to its wholesale and retail customers. (Note: this program is currently closed.) 
- Nonprofit programs in Massachusetts (Mass Energy Consumers Alliance) and Rhode Island (People's Power \& Light) purchase RECs from PV systems at $\$ 0.06 / \mathrm{kWh}$ for three years. The RECs are packaged together with wind, small hydro and biomass renewable energy certificates and sold as New England GreenStartSM, a green power product offered by National Grid.

- The Energy Cooperative Association of Pennsylvania (ECAP), a nonprofit, Philadelphia-based competitive energy supplier, pays PV system owners $\$ 0.28 / \mathrm{kWh}$ for a 2-year contract who are ECAP customers for the combined RECs and electricity. These customers must purchase $100 \%$ green power through ECAP. PECO customers may also participate, receiving $\$ 0.10 / \mathrm{kWh}$ for 2 years. Output from participating systems provides the solar component of ECAP's Green-e certified product, "EcoChoice100".

\section{Utility PV Incentive Programs}

Salt River Project (SRP), Sacramento Municipal Utility District (SMUD) and the Los Angeles Department of Water \& Power have developed EPBB programs. SMUD offers a capacity-based rebate of $\$ 3 / \mathrm{W}$, adjusted for expected performance. LADWP's recently launched EPBB is structured as an expected production-based incentive. The incentive rate ranges from $\$ 0.04 / \mathrm{kWh}$ to $\$ 0.16 / \mathrm{kWh}$ depending on system size, tax status, customer type, and other factors. Ownership of the RECs associated with PV production is granted to the utility. SRP is one of the first programs to implement field verification with their EPBB incentive. 


\section{Appendix B: Verification Provided by Incentive Structures}

\section{Introduction}

This appendix presents the typical method used to calculate a PBI payment and then expands upon this calculation by adding a series of interim steps to explicitly identify performance-related issues. The first subsection presents how a PBI rate is established and then uses that rate to calculate the total incentive under the PBI structure. The second subsection expands the PBI incentive calculation to include a set of adjustment factors.

For illustration purposes, it is assumed that the PBI has a fixed rate and one year duration so that payment is made in full at the end of first year of operation. An extension to this derivation would take into account multiple-year programs.

\section{Variable Definitions}

It is useful to begin with a specification of the terms that will be used in analysis.

The terms "actual" and "ideal" occur multiple times in the variables specified below.

"Actual" refers to the actual system that is installed. "Ideal" refers to the following:

- Ideal capacity is the reported capacity used in the PBI rate calculation.

- Ideal system design is the system with the configuration that maximizes energy production for a given location (e.g., if only fixed systems are considered, this is a system oriented to maximize energy production with no shading).

- Ideal location is the geographical location within the applicable incentive territory that has the highest potential PV energy production.

- Ideal weather data is the long-term data set used for performance modeling, such as NREL's TMY data.

Now consider each of the variables.

$\mathrm{R}=$ Incentive revenue required by customer (\$ per $\mathrm{kW}$ for ideal system)

$\mathrm{R}$ represents the capacity-based incentive revenue (\$ per $\mathrm{kW}$ ) that the granting agency will pay for an ideal system in the ideal location based on an ideal weather data set. $\mathrm{R}$ is the result of a separate analysis and needs to consider the effect of non-ideal conditions (rating, design, location, etc.) under which most customers will invest. It is expressed in units of $\$$ per $\mathrm{kW}$ of ideal capacity. The measured data will adjust for non-ideal conditions.

$\mathrm{C}_{\mathrm{I}}=$ Ideal capacity $(\mathrm{kW})$ to produce ideal output $\mathrm{E}_{\mathrm{I}, \mathrm{I}, \mathrm{S}, \mathrm{I}}-$ defined below $(\mathrm{kWh})$

$\mathrm{C}_{\mathrm{A}}=$ Actual capacity $(\mathrm{kW})$ to produce actual output $\mathrm{E}_{\mathrm{A}, \mathrm{A}, \mathrm{M}}-$ defined below (kWh) 
$\mathrm{C}$ refers to system capacity. The capacity can be based on the ideal capacity $\left(\mathrm{C}_{\mathrm{I}}\right)$ required to produce an ideal amount of energy or the actual capacity $\left(\mathrm{C}_{\mathrm{A}}\right)$ required to produce an actual amount of energy.

\section{Design Location Method Weather Capacity}

\begin{tabular}{|c|c|c|c|c|c|c|c|}
\hline & & & & & \multicolumn{3}{|c|}{ Data } \\
\hline $\mathrm{E}_{\mathrm{A}, \mathrm{A}, \mathrm{M}}$ & $=$ & Output (kWh) & Actual & Actual & Measured & N/A & $\mathrm{C}_{\mathrm{A}}$ \\
\hline $\mathrm{E}_{\mathrm{I}, \mathrm{I}, \mathrm{S}, \mathrm{I}}$ & $=$ & Output (kWh) & Ideal & Ideal & Simulated & Ideal & $\mathrm{C}_{\mathrm{I}}$ \\
\hline $\mathrm{E}_{\mathrm{A}, \mathrm{A}, \mathrm{S}, \mathrm{I}}$ & $=$ & Output (kWh) & Actual & Actual & Simulated & Ideal & $\mathrm{C}_{\mathrm{I}}$ \\
\hline $\mathrm{E}_{\mathrm{I}, \mathrm{A}, \mathrm{S}, \mathrm{I}}$ & $=$ & Output (kWh) & Ideal & Actual & Simulated & Ideal & $\mathrm{C}_{\mathrm{I}}$ \\
\hline $\mathrm{E}_{\mathrm{A}, \mathrm{A}, \mathrm{S}, \mathrm{A}}$ & $=$ & Output (kWh) & Actual & Actual & Simulated & Actual & $\mathrm{C}_{\mathrm{I}}$ \\
\hline
\end{tabular}

$\mathrm{E}$ is the amount of energy produced. There are five different ways that $\mathrm{E}$ can be estimated/calculated, which are represented by the term $\mathrm{E}$ with various subscripts. The subscripts correspond to design, geographical location, calculation method, and weather data set. The first term is a measured value and the remaining four terms are simulated outputs.

\section{PBI Incentive}

Calculating an incentive payment under a PBI structure is accomplished in three steps. First, the granting agency determines how much it will pay for an ideal system. Second, the PBI rate is set by dividing the incentive by the amount of energy that an ideal system is expected to produce. Third, the PBI rate is multiplied by measured energy production to determine the total incentive payment. Notice that, while the output is measured, the PBI rate is established through the use of a set of assumptions and simulated data designed to encourage optimal performance.

The first step is to determine how much the granting agency is willing to pay (R) for an ideal system $(\$ / \mathrm{kW})$. An ideal system is perfectly rated, has the optimal orientation with no shading, is located in the geographical location with best solar resource, and operates with perfect reliability. The ideal payment amount is determined by a separate analysis and must take into account the fact that customers will typically receive lower payments due to non-ideal conditions. The amount needs to be set high enough to attract a sufficient number of customers to participate in the program.

Second, the specified incentive is divided by the amount of energy that an ideal system (with an ideal capacity) is expected to produce $(\mathrm{kWh}$ per $\mathrm{kW})$ in order to determine the PBI rate. Finally, after the system has been in operation for some period of time defined by the granting agency, the PBI rate is multiplied by the measured energy produced by the system. The result is the payment amount to the system owner.

$$
\text { Incentive }=[\text { PBI Rate }][\text { Measured Production }]=\overbrace{(R)\left(\frac{1}{E_{I, I, S, I}}\right)\left(C_{I}\right) \times \overbrace{\left(E_{A, A, M}\right)}^{\text {PBI }} \begin{array}{c}
\text { Measured } \\
\text { Production }
\end{array}}^{\text {Rate }}
$$


As described above, $\mathrm{E}_{\mathrm{I}, \mathrm{I}, \mathrm{S}, \mathrm{I}}$ is the output for a system with capacity $\mathrm{C}_{\mathrm{I}}$ based on an ideal design (first I subscript), at the ideal location (second I subscript), simulated with a model (S subscript), using ideal weather data (last I subscript).

\section{Expand PBI Calculation Equation}

The PBI calculation can be expanded to provide a better understanding of the performance issues that it mitigates. This is accomplished by multiplying Equation (1) by the following ratios ${ }^{26}$ and then rearranging.

- $\mathrm{C}_{\mathrm{I}} / \mathrm{C}_{\mathrm{I}}$

- $\mathrm{C}_{\mathrm{A}} / \mathrm{C}_{\mathrm{A}}$

- $\mathrm{E}_{\mathrm{A}, \mathrm{A}, \mathrm{S}, \mathrm{I}} / \mathrm{E}_{\mathrm{A}, \mathrm{A}, \mathrm{S}, \mathrm{I}}$

- $\mathrm{E}_{\mathrm{I}, \mathrm{A}, \mathrm{S}, \mathrm{I}} / \mathrm{E}_{\mathrm{I}, \mathrm{A}, \mathrm{S}, \mathrm{I}}$

- $\mathrm{E}_{\mathrm{A}, \mathrm{A}, \mathrm{S}, \mathrm{A}} / \mathrm{E}_{\mathrm{A}, \mathrm{A}, \mathrm{S}, \mathrm{A}}$

The result presented in Equation (2) is that the total PBI-based incentive equals an Incentive Revenue $(\$ / \mathrm{kW})$ times ideal system capacity $(\mathrm{kW})$ times five adjustment factors. The details of each of the terms are described below, as well as how to apply this equation in different situations.

$$
\begin{aligned}
& \text { Incentive }= \\
& \text { Incentive System Rating Design Location Availability Weather } \\
& \text { Revenue Capacity Factor Factor Factor Factor Factor } \\
& \overbrace{(R)}^{(R)} \times \overbrace{\left(C_{I}\right)} \times \overbrace{\left(\frac{C_{A}}{C_{I}}\right)}^{\left(\frac{E_{A, A, S, I}}{E_{I, A, S, I}}\right)} \times \overbrace{\left(\frac{E_{I, A, S, I}}{E_{I, I, S, I}}\right)}^{\mathrm{s}} \times \overbrace{\left(\frac{\mathrm{E}_{\mathrm{A}, \mathrm{A}, \mathrm{M}} / C_{A}}{\mathrm{E}_{\mathrm{A}, \mathrm{A}, \mathrm{S}, \mathrm{A}} / C_{I}}\right)}^{\mathrm{F}} \times \overbrace{\left(\frac{\mathrm{E}_{\mathrm{A}, \mathrm{A}, \mathrm{S}, \mathrm{A}}}{E_{A, A, S, I}}\right)}^{\mathrm{F}} \\
& \text { Similar to } \mathrm{CBB} \\
& \text { One-time Issues } \\
& \text { Recurring Issues }
\end{aligned}
$$

Where

$\mathrm{C}=$ Capacity $_{\text {A or I }}$

$E=$ Energy Design (A or I), Location (A or I), Method (M or S), Weather Data (A or I)

$\mathrm{A}=$ Actual

$\mathrm{I}=$ Ideal

$\mathrm{M}=$ Measured

$\mathrm{S}=$ Simulated

\section{One-Time Issues}

\section{Rating Factor}

The Rating Factor accounts for inaccuracies in system rating methods, rating conventions, and the effects of varying system installation practices. One way to

\footnotetext{
${ }^{26}$ Multiplying by a series of $1 \mathrm{~s}$ does not change the value of the equation.
} 
measure the actual system rating is to dispatch an independent inspector to the site to measure the actual rating once the system is commissioned. Another approach is to base the system rating on measured output and weather conditions over some period of time. The utility could collect measured data for this period and compare it to a simulation model using actual time-correlated weather data corresponding to the location of the system.

If the second approach is taken, there are some practical difficulties that need to be addressed in order to perform this calculation. The selection of PV simulation model and weather data set (measured on site, satellite, other?) would have to be determined and explained in the program terms. Also, if the PV system were to become unavailable during the test period, there must be some means to determine this and repeat the test. ${ }^{27}$ Note that a separate meter for the PV system would be required to measure energy over the test period.

\section{Design and Location Factors}

The Design and Location factors are based solely on simulated data using ideal (longterm) weather data for a system with the same ideal capacity. Since these are simulated quantities, as long as the same model and weather data are used, the factor calculations do not require high precision in the PV simulation model or weather data set; inaccuracies in the simulation will tend to cancel each other out.

Thus, it should be sufficient to use an industry accepted model that can account for location, orientation, and shading ${ }^{28}$ and a long-term data set such as NREL's typical meteorological year (TMY) ${ }^{29}$ or similar data set, as determined by the agency. In addition, performing a one-year simulation based on TMY data should be sufficient to determine the impact of system design on output over the life of the system (again, the factor takes the ratio of two simulations).

\section{Recurring Issues}

\section{Availability Factor}

The Availability Factor accounts for long-term system availability relative to a defined standard. All parts of the system must be in working order and the overall system must be well maintained over the long-term in order for the owner to maximize the incentive payments. This factor requires measured system output and the corresponding measured weather data over the long-term, and the method of simulating output must be defined in advance of program implementation. Note that this factor cannot be estimated using a short-term data set.

\footnotetext{
${ }^{27}$ The agency might, for example, give the incentive applicant the right to request up to two additional measurements of the Rating Factor. To avoid extra administrative burden, the final value that is calculated is the one that is used to determine the rebate.

${ }^{28}$ A model such as the Clean Power Estimator should be sufficient because it accounts for both orientation and shading for multiple sub-system orientations. An alternative would be PVWATTS (combined with a suitable shading program).

${ }^{29} \mathrm{http}$ ://www.eere.energy.gov/buildings/energyplus/weatherdata_sources.html\#TMY2
} 


\section{Weather Factor}

The Weather Factor accounts for variations in weather trends over the long-term. This factor requires simulated system performance based on actual weather data versus simulated performance based on ideal (long-term) weather data. As with the Availability Factor, the Weather Factor cannot be estimated using a short-term data set.

\section{Application to Incentive Design}

The PBI structure is the one that guarantees that a granting agency only pays for the energy it receives. It places the burden for one-time issues (system rating, design, and location) and recurring issues (availability and weather variability) on the PV system owner.

There may be some circumstances when a granting agency does not want to transfer full responsibility for all issues to the system owner. For example, it might prefer that a homeowner not bear the risk of weather variability. In this case, the PBI rate would be adjusted to eliminate the Weather Factor. As another example, an agency may want to offer an upfront payment to avoid the administrative burden of metering and billing under a PBI program. It may elect to adjust only for one-time performance issues but not for the recurring issues. In this case, only the one-time factors would be used. Each agency must asses which combination of factors makes the most sense for their program. 


\section{Appendix C: PV System Rating Conventions}

Incentive programs that use rated capacity as part of the payment basis must define a system power rating convention or select one from existing conventions. Most programs currently use component-based ratings. Some use a component-based DC system rating (the nameplate rating of the PV modules times the number of modules). Others use a component-based AC rating defined by the California Energy Commission (AC-CEC) this rating equals the PV module rating under PVUSA Test Conditions ${ }^{30}$ times the number of modules times the weighted average inverter efficiency and is referred to as the AC-CEC rating.

Component-based ratings may provide accurate standards but they are difficult to validate after systems have been installed. For example, in the case of the AC-CEC rating, it is difficult to separately measure the PVUSA Test Conditions rating of the modules and then to measure the efficiency of the inverter. The situation is analogous to evaluating the fuel efficiency of a car. While each of the components within a car has an efficiency rating (engine, transmission, etc.), a car's miles per gallon is based on the complete system. In order to verify a car's mileage, one would take the car out under the established rating conditions and actually test the car. It is difficult to determine the efficiency of just the engine once it has been installed in a vehicle.

In order to establish an incentive based on performance, an incentive program should consider using a rating that can be physically verified after the system has been installed. If this approach is taken, the $\mathrm{AC}$ rating would be based on the rating of the entire system, not just the components. Such a rating is referred to as the system AC rating. If it so desired, the incentive program could then base the incentive payment on the verified rating, thus rewarding manufacturers and installers of high quality systems. Consumers could also be equipped with a tool to assess instantaneous system performance.

Implementing a system AC rating requires the acceptance of a verification protocol. While specification of a protocol is beyond the scope of this Handbook, some protocols exist. The protocol needs to identify the required on-site measurements (e.g., irradiance, module temperature, power output), testing period (instantaneous versus some time period), and how to translate those measurements into a system AC rating.

While the verified rating could be used to pay the incentive, all incentive structures need an estimated system rating in order to reserve the appropriate amount of incentive funds, once an application has been submitted. A system AC rating convention was proposed by the California Public Utilities Commission (CPUC) staff [12] in calculating the Expected Performance Based Buydown for systems under $100 \mathrm{~kW} .^{31}$ The System Rating is the $\mathrm{AC}$ rating of the entire installed system as defined under PVUSA Test Conditions.

\footnotetext{
${ }^{30} \mathrm{PV}$ USA Test Conditions are at $1,000 \mathrm{Watt} / \mathrm{m}^{2}$ solar irradiance, $20^{\circ}$ Celsius ambient temperature, and 1 meter per second wind speed.

${ }^{31}$ Subsequent recommendations by the Staff have been to use the AC-CEC rating until a verification protocol has been accepted.
} 
The Estimated Rating is calculated as follows:

Estimated Rating = Number Modules $x$ PV PTC Module Rating $x$ Inverter Efficiency $x$ Other Loss Factor (Assumed to be 90\%)

For reference purposes, the derating from DC to the AC-CEC rating is typically about 85.5 percent and the derating from DC to system AC (under PV USA Test Conditions) is about 77 percent. The derating from AC-CEC to AC is about 90 percent, thus accounting for the Other Loss Factor. 


\section{Appendix D: Incentive Design That Maintains Constant Cost- Effectiveness}

This appendix describes how to design an incentive that maintains a constant level of cost-effectiveness for all customers entering the program at any point over its duration. This approach would be taken by incentive agencies with the goal to subsidize PV only to the extent of its defined cost-effectiveness test. In an environment of declining PV prices, the incentive would likewise decline. This approach differs from one in which incentive agencies seek to increase market demand to correspond with increasing costeffectiveness.

While there are different measures of cost-effectiveness, the present analysis uses a zero net present value of cash flows over the life of the system. It is further simplified by considering only the capital cost, utility bill savings and incentive amounts. That is, the analysis assumes that the incentive amount is calculated such that the customer "breaks even" when considering the present value of these cash flows.

For purposes of illustration, the derivation assumes a variable duration, variable rate PBI structure. This simplifies the problem because the incentive structure is independent of the year in which the customer invests; customers who wait to invest forgo the PBI payments associated with the previous years.

The appendix begins with a simple example, then presents the detailed mathematical formulation, and then concludes with hypothetical numerical results.

\section{Optimization Problem}

The incentive design is determined by formulating a constrained optimization problem. The incentive agency wants to maximize its benefits minus cost, subject to the following goals and constraints:

- Incentive program cost does not exceed program budget at any point in time

- The incentive rate is sufficient for customers to invest immediately

- The PBI structure compensates for predicted lower PV prices thus eliminating the motivation for customers to wait before investing

- The agency is indifferent as to whether systems perform as predicted (or are even removed entirely)

Rather than formulating the general optimization problem, this appendix focuses on the constraints since they are critical in designing the PBI structure. 


\section{Example}

Consider an example PBI design problem. Suppose that the incentive agency desires $165,000 \mathrm{kWh}$ of PV-generated electricity per year and that a customer is considering investing in a PV system. Assume:

- The current year is 2007

- A $100 \mathrm{~kW}$ system will produce $165,000 \mathrm{kWh}$ per year

- A $100 \mathrm{~kW}$ system costs $\$ 600,000$ in 2007 and will cost $\$ 550,000$ in 2008

- The only other benefit a customer gains from investing in PV is the utility bill savings; that is, all tax effects are excluded

- A $100 \mathrm{~kW}$ system reduces the current annual utility bill by $\$ 20,000$ and these savings escalate at a rate of 3 percent per year

- PV system life is 30 years

- The PBI payments will last some currently unknown period (but less than 30 years)

- The discount rate is 10 percent

The agency wants to determine what the PBI rate should be for 2007 .

Table 6 presents the cash flows associated with the two investment alternatives that are available to the customer under a given PBI set of rules. The top part of the table is the "Buy Now" alternative and the bottom part of the table is the "Wait 1 Year" alternative. If the customer purchases immediately, the utility bill savings will be $\$ 20 \mathrm{~K}$ in 2007 , $\$ 20.6 \mathrm{~K}$ in 2008 , etc., the customer will receive the PBI for some number of years, and the customer will incur an immediate cost of $\$ 600 \mathrm{~K}$. If the customer delays investment for one year, the utility bill will be reduced by $\$ 20.6 \mathrm{~K}$ in $2008, \$ 21.2 \mathrm{~K}$ in 2009 , etc., the customer will receive the (now slightly lower) PBI, and for one less year, and the customer will incur a cost of $\$ 550 \mathrm{~K}$ in 2008 .

Notice that there is very little difference between the cash flows for the two alternatives. The only differences are that a customer choosing the "Buy Now" alternative (i) saves on the utility bill immediately, (ii) receives a PBI payment in 2007, and (iii) incurs the higher system cost in 2007 while a customer choosing the "Wait 1 Year" alternative (i) adds a year of utility bill savings after 30 years (ii) forfeits the 2007 PBI payment, and (iii) incurs a lower system cost one year later in 2008.

In order to provide the customer with the proper investment incentive in 2007, the agency needs to set the incentive amounts so that there is no economic benefit for customers between buying now and waiting. This would occur when the two cash flow streams are equal in net present value terms.

The difference between the cash flows for the two alternatives is shown in the top of Table 7 and the discounted difference is shown in the bottom part of the table. An examination of the bottom part of the table indicates that the only way to make the sum of the net discounted cash flows equal to $\$ 0$ (so that there is no economic benefit in waiting to invest) is to set the 2007 incentive at $\$ 82.8 \mathrm{~K}$, so that it satisfies the equation 0 
$=\mathrm{I}_{2007}-\$ 580 \mathrm{k}+\$ 500 \mathrm{k}-\$ 2.8 \mathrm{k}$. As a $100 \mathrm{~kW}$ system produces $165,000 \mathrm{kWh}$, per year, this corresponds to a PBI payment of $50 \notin$ per $\mathrm{kWh}$ in 2007.

The next section will demonstrate how to establish the full PBI structure.

Table 6. Cash flows associated with two investment alternatives.

\begin{tabular}{|c|c|c|c|c|c|c|}
\hline & 2007 & 2008 & 2009 & $\ldots$ & 2036 & 2037 \\
\hline \multicolumn{7}{|l|}{ Buy Now } \\
\hline Bill Savings & $\$ 20 \mathrm{~K}$ & $\$ 20.6 \mathrm{~K}$ & $\$ 21.2 \mathrm{~K}$ & $\ldots$ & $\$ 47.1 \mathrm{~K}$ & \\
\hline Incentive & $\mathrm{I}_{2007}$ & $\mathrm{I}_{2008}$ & $\mathrm{I}_{2009}$ & $\ldots$ & & \\
\hline System Cost & $-\$ 600 \mathrm{~K}$ & & & & & \\
\hline \multicolumn{7}{|l|}{ Wait 1 Year } \\
\hline Bill Savings & & $\$ 20.6 \mathrm{~K}$ & $\$ 21.2 \mathrm{~K}$ & $\ldots$ & $\$ 47.1 \mathrm{~K}$ & $\$ 48.5 \mathrm{~K}$ \\
\hline Incentive & & $\mathrm{I}_{2008}$ & $\mathrm{I}_{2009}$ & $\ldots$ & & \\
\hline System Cost & & $-\$ 550 \mathrm{~K}$ & & & & \\
\hline
\end{tabular}

Table 7. Difference between "Buy Now" versus "Wait 1 Year" cash flows.

\begin{tabular}{|l|c|c|c|c|c|c|}
\cline { 2 - 7 } \multicolumn{1}{c|}{} & 2007 & 2008 & 2009 & $\ldots$ & 2036 & 2037 \\
\hline \multicolumn{2}{|c|}{ Difference: Buy Now Minus Wait 1 Year } \\
\hline Net & $\begin{array}{c}\mathbf{I}_{\mathbf{2 0 0 7}-} \\
\mathbf{\$ 5 8 0 K}\end{array}$ & $\mathbf{\$ 5 5 0 K}$ & 0 & $\ldots$ & 0 & $\mathbf{- \$ 4 8 . 5 K}$ \\
\hline $\begin{array}{l}\text { Net } \\
\text { (Discounted) }\end{array}$ & $\begin{array}{c}\mathbf{I}_{\mathbf{2 0 0 7}-} \\
\mathbf{\$ 5 8 0 K}\end{array}$ & $\mathbf{\$ 5 0 0 K}$ & 0 & $\ldots$ & 0 & $\mathbf{- \$ 2 . 8 K}$ \\
\hline
\end{tabular}




\section{Constrained Optimization Problem}

The simple example above produced the incentive amount in 2007 in order to provide customers with no economic benefit in waiting until 2008 to invest. Several questions still remain. First, what should the PBI rate be after 2007? Second, how many years should the PBI payments be made? This section formalizes the concepts presented above to derive an expression for the incentive payment in any given year.

The PBI structure needs to be designed to satisfy two criteria. First, for every year of the program, a customer should be economically indifferent between investing and waiting. Second, the PBI payments should continue until a defined cost-effectiveness test has been satisfied.

\section{Value to Customer}

Consider the value of a PV investment that occurs either now or at some time in the future. The value (expressed in $\$ / \mathrm{kW}$ ) of waiting W years to invest (neglecting tax effects and O\&M costs) equals the present value of the utility bill savings over the life of the PV system plus the present value of the PBI payments minus the system price. That is,

$$
\begin{gathered}
\begin{array}{c}
\text { Value of } \\
\text { Yearting } W
\end{array} \\
\text { Year }
\end{gathered}=\overbrace{\sum_{t=W}^{L-1+W} \frac{U_{t} E_{t}}{(1+r)^{t}}}^{\text {Utility Bill Savings }}+\overbrace{\sum_{t=W}^{D-1} \frac{I_{t} E_{t}}{(1+r)^{t}}}^{\text {Performance Based Incentives }}-\overbrace{\frac{P_{W}}{(1+r)^{W}}}^{\text {Price }}
$$

where:

- $t$ is the year

- $U_{t}$ is the effective utility bill savings ( $\$$ per $\mathrm{kWh}$ ) including the impacts of demand charge savings, net metering, and net production

- $I_{t}$ is the performance based incentive (\$ per $\mathrm{kWh}$ )

- $E_{t}$ is the energy produced by the PV system (kWh per $\mathrm{kW}$ per year)

- $L$ is the life of the PV system (years)

- $W$ is the number of years that the customer waits before investing (years)

- $\mathrm{r}$ is the customer's discount rate (percent)

- $D$ is the PBI program duration (years)

- $P_{W}$ is the price of the PV system in year $W(\$ \text { per } \mathrm{kW})^{32}$

This analysis also assumes that, with the declining cost of PV installations and the increasing utility costs, PV will become cost effective without further subsidies within the service life of PV systems installed today. That is, the PBI program duration (D) is shorter than PV system life (L).

\footnotetext{
${ }^{32}$ This analysis does not include tax effects. The fundamental conclusions, however, will still be valid when those effects are included.
} 


\section{First Constraint: No Benefit in Waiting}

The first criterion is that a customer needs to be economically indifferent to the year in which the investment is made over the duration of the PBI. This is satisfied when the value to the customer given by Equation (3) is the same whether the customer invests now $(\mathrm{W}=0)$ or the customer invests later $(\mathrm{W}>0)$. If it is assumed that the energy production $\mathrm{E}$ is constant over time, the customer is indifferent when:

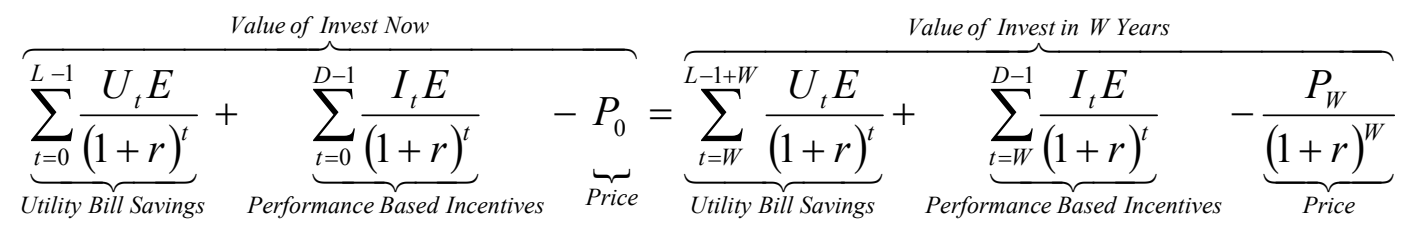

Many of the terms are the same on both sides of Equation (4) and the terms cancel. The result is that

$$
\sum_{t=0}^{W-1} \frac{I_{t} E}{(1+r)^{t}}=P_{0}-\frac{P_{w}}{(1+r)^{W}}-\left\{\sum_{t=0}^{W-1} \frac{U_{t} E}{(1+r)^{t}}-\sum_{t=L}^{L+W-1} \frac{U_{t} E}{(1+r)^{t}}\right\}
$$

This can be rewritten by expanding the price terms to create a summation and by modifying the second utility bill savings summation in order to have all of the summation terms begin at 0 and end at $\mathrm{W}-1$ years.

$$
\sum_{t=0}^{W-1} \frac{I_{t} E}{(1+r)^{t}}=\sum_{t=0}^{W-1}\left[\frac{P_{t}}{(1+r)^{t}}-\frac{P_{t+1}}{(1+r)^{t+1}}\right]-\left\{\sum_{t=0}^{W-1} \frac{U_{t} E}{(1+r)^{t}}-\sum_{t=0}^{W-1} \frac{U_{L+t} E}{(1+r)^{L+t}}\right\}
$$

The incentive for each year is calculated by varying $\mathrm{W}$ from 1 to the PBI duration $\mathrm{D}$ and then substituting back into Equation (6) for each previously defined $I_{t}$. The result is that the PBI for any particular year is the cost premium of not waiting for the following year's price reduction less the added upfront utility savings benefits, or:

$$
I_{t}=\overbrace{\left[\left(P_{t}-\frac{P_{t+1}}{1+r}\right)\left(\frac{1}{E}\right)\right]}^{\text {Cost Premium }}-\overbrace{\left[U_{t}-\frac{U_{L+t}}{(1+r)^{L}}\right]}^{\text {Added Benefit }}
$$

\section{Second Constraint: Cost-Effectiveness Test}

The second criterion is that the PBI payments should continue until some costeffectiveness test has been met based upon forecasted prices and market conditions. This test could be based on the net present value, simple payback, rate of return, or some other test in an unsubsidized market. The incentive rate is calculated using Equation (7) for each year $t$ until the year in which the investment is expected to be cost-effective and then it is equals 0 after that point. 


\section{Incentive Result}

When these two criteria are satisfied, the result is that the PBI rate for any particular year equals the cost premium of not waiting for the following year's price reduction less the added upfront utility savings benefits. The payments continue until the year that the costeffectiveness test is satisfied in an unsubsidized market. The result is as follows:

$$
I_{t}= \begin{cases}\overbrace{\left[\left(P_{t}-\frac{P_{t+1}}{1+r}\right)\left(\frac{1}{E}\right)\right]}^{\text {Cost Premium }}-\overbrace{\left[U_{t}-\frac{U_{L+t}}{(1+r)^{L}}\right]}^{\text {Added Benefit }} & \text { for } t<D \\ 0 & \text { for } t>=D\end{cases}
$$

In this relationship, the "Cost Premium" is the premium the customer would have to pay to invest in year $t$ rather than wait for a lower (discounted) price the following year $t+1$. The "Added Benefit" is the utility bill savings gained from investing in year $t$ versus waiting for the following year. As desired, the optimum PBI payment $I_{t}$ provides only the incremental additional incentive the customer would require to in order to invest in the given year.

Suppose, for example, that the current price of a PV system is $\$ 6,000$ per $\mathrm{kW}$ and the price next year is expected to be $\$ 5,500$ per $\mathrm{kW}$. Assume that the system produces 1,650 $\mathrm{kWh}$ per $\mathrm{kW}$ per year, the utility bill savings rate is $12 \notin$ per $\mathrm{kWh}$ currently and $30 \notin$ per $\mathrm{kWh}$ in 30 years, and the discount rate is 10 percent. Equation (8) suggests that the "Cost Premium" is $60 \notin$ per $\mathrm{kWh}$, the "Added Benefit" is $10 \phi$ per $\mathrm{kWh}$, and the PBI rate is the difference between the two and equals $50 \notin$ per $\mathrm{kWh}$.

In order to have a positive incentive, the "Cost Premium" due to waiting in Equation (8) must exceed the "Added Benefit" due to investing immediately. There are cases, however, where the PV price is actually increasing. For example, suppose that rather than decreasing, the price of $\mathrm{PV}$ is expected to increase by 5 percent from $\$ 8,000$ per $\mathrm{kW}$ to $\$ 8,400$ per $\mathrm{kW}$ over the course of a year. Assume that the discount rate is 10 percent and the system produces 1,650 kWh per kW per year. The "Cost Premium" equals $22 \varnothing$ per $\mathrm{kWh} .{ }^{33}$ If the current utility rate is $10 \phi$ per $\mathrm{kWh}$ and is expected to be $25 \phi$ per $\mathrm{kWh}$ in 30 years, the "Added Benefit" equals $8 \notin$ per $\mathrm{kWh}^{34}$ and the incentive rate should be set at $14 \phi$ per $\mathrm{kWh}$. Conversely, if the current utility rate is $30 \phi$ per $\mathrm{kWh}$ and is expected to be $60 \notin$ per $\mathrm{kWh}$ in 30 years, the "Added Benefit" equals $26 \notin$ per $\mathrm{kWh}^{35}$ and the incentive rate should be set at $0 \notin$ because the "Added Benefit" exceeds the "Cost Premium".

\section{Verification}

The PBI payments are intended to provide a customer with the incentive to purchase PV, an otherwise uneconomic investment, until such time as the price of PV drops to a costcompetitive level and subsidies are no longer required. To minimize the cost to the utility

\footnotetext{
${ }_{33}(\$ 8,000-\$ 8,400 / 1.1) / 1,650=22 \phi$.

${ }^{34} 10 \phi-25 \phi / 1.1^{\wedge} 30=8 \phi$.

${ }^{35} 30 \phi-60 \phi / 1.1^{\wedge} 30=26 \phi$.
} 
(and its ratepayers), the value of these payments should equal, but should not exceed, the economic shortfall. This section demonstrates that the PBI structure provides the correct value to achieve this balance.

Under such a balanced PBI structure, the customer would be considered to "break even" provided that the "Wait to Invest" alternative (in which the investment is made in a year $\mathrm{W})$ resulted in the same value as a future, cost-competitive, unsubsidized PV system. By definition, this would first occur in year D, the year following the conclusion of the PBI program. Thus, it needs to be demonstrated that the customer investing in year $\mathrm{W}$ is made whole, deriving the same value as the customer investing in year D.

The value of the "Wait to Invest" alternative is given by Equation (3) for any year W less than or equal to $\mathrm{D}$ with the assumption that the energy production $\mathrm{E}$ for any year is the same. The PBI structure from Equation (8) is substituted into Equation (3) (where $t<D$ ).

As shown below, the result is that the value of the "Wait to Invest" alternative is equal to the value of an investment in year D, discounted to the current year. The conclusion is that PBI structure provides the correct level of subsidy to ensure that the early investment for any year between 0 and $\mathrm{D}$ is economically equivalent to the future, unsubsidized investment.

That is, the value of investing at any time over the duration of the PBI program equals the value of the investment in the year after the PBI payments cease (year D), discounted to the current year. 


$$
\begin{aligned}
& \begin{array}{l}
\text { Value of } \\
\text { Investing in } \\
\text { Year } W
\end{array}=\sum_{t=W}^{L-1+W} \frac{U_{t} E}{(1+r)^{t}}+\sum_{t=W}^{D-1} \frac{I_{t} E}{(1+r)^{t}}-\frac{P_{W}}{(1+r)^{W}} \\
& =\sum_{t=W}^{L-1+W} \frac{U_{t} E}{(1+r)^{t}}+\sum_{t=W}^{D-1} \frac{\left\{\left[\left(P_{t}-\frac{P_{t+1}}{1+r}\right)\left(\frac{1}{E}\right)\right]-\left[U_{t}-\frac{U_{L+t}}{(1+r)^{L}}\right]\right\} E}{(1+r)^{t}}-\frac{P_{W}}{(1+r)^{W}} \\
& =\sum_{t=W}^{L-1+W} \frac{U_{t} E}{(1+r)^{t}}+\sum_{t=W}^{D-1}\left[\frac{P_{t}}{(1+r)^{t}}-\frac{P_{t+1}}{(1+r)^{t+1}}\right]-\sum_{t=W}^{D-1}\left[\frac{U_{t} E}{(1+r)^{t}}-\frac{U_{L+t} E}{(1+r)^{L+t}}\right]-\frac{P_{W}}{(1+r)^{W}} \\
& =\sum_{t=D}^{L-1+W} \frac{U_{t} E}{(1+r)^{t}}+\sum_{t=L+W}^{L+D-1} \frac{U_{t} E}{(1+r)^{t}}-\frac{P_{D}}{(1+r)^{D}} \\
& =\sum_{t=D}^{L+D-1} \frac{U_{t} E}{(1+r)^{t}}-\frac{P_{D}}{(1+r)^{D}} \\
& \text { Present Value of } \\
& \text { Investment in Year D } \\
& \text { Discount to } \\
& =\overbrace{\left[\sum_{t=0}^{L-1} \frac{U_{t+D} E}{(1+r)^{t}}-P_{D}\right]}^{\left[\frac{1}{(1+r)^{D}}\right]}
\end{aligned}
$$




\section{Variable Specification}

The PBI rate structure can be completely specified using Equation (8). There are, however, several variables that are unknown in the current year. These variables include future utility bill savings and PV system prices.

\section{Future Utility Bill Savings}

It will be assumed that utility bills savings will escalate at a consistent rate $(e)$ over time so that the utility bill savings at time $t$ is a function of the utility bill savings at time 0 .

$$
U_{t}=U_{0}(1+e)^{t}
$$

\section{PV System Price}

While PV system prices could be assumed to decline from time 0 at a fixed percentage, a more accurate approach would be to use a learning curve price model. A good review of learning curve price models can be found in [1]. The author, Margolis, provides a brief review of the literature that examines learning by doing, learning by using, and experience curves. The general form of the experience curve as applied to price estimates is:

$P_{t}=P_{0}\left[\frac{Q_{t}}{Q_{0}}\right]^{\frac{\ln (P R)}{\ln (2)}}$

where $Q_{t}$ is the cumulative quantity of installed PV capacity at time $\mathrm{t}$ and PR is the progress ratio. The Progress Ratio for crystalline PV modules is currently estimated to be 0.82 . A 0.82 progress ratio indicates that the price is reduced by 18 percent for a doubling of cumulative PV capacity. It is important to note that the price is sensitive to this progress ratio assumption.

Using this formula, future PV capital costs are estimated based upon today's cost and an estimate of future production. ${ }^{36}$

\footnotetext{
${ }^{36}$ While the progress ratio presents the price in real terms, it will be used for the nominal price projection due to uncertainty in what is the correct progress ratio for a complete PV system rather than PV modules alone (see [1] for a presentation of the range of progress ratios for PV prices).
} 


\section{Sample PBI Results}

The PBI structure can be calculated based on the assumptions presented in Table 8 using Equations (8), (9), and (10). ${ }^{37}$ While other cost-effectiveness tests could be used, it is assumed that the PV investment is cost-effective (and thus the point at which a PBI is no longer paid) when the PV Price is less than or equal to 10 times the corresponding year's utility bill savings (i.e., the investment has a 10 year simple payback). The results are summarized in Table 9 and Figure 13. For this particular set of assumptions, the result is an optimized 13-year PBI that starts at $47 \phi$, and declines to $10 \phi$ in the final year.

Table 8. Assumptions.

\begin{tabular}{|c|c|}
\hline \multicolumn{2}{|l|}{ Utility Savings } \\
\hline Average Utility Savings $\left(U_{0}\right)$ & $\$ 0.12$ per $\mathrm{kWh}$ \\
\hline Savings Escalation (e) & $3 \%$ per year \\
\hline PV Is Cost Effective When & 10 yrs savings > cost \\
\hline \multicolumn{2}{|l|}{ PV System } \\
\hline Effective Price $\left(P_{0}\right)$ & $\$ 6,000$ per $\mathrm{kW}$ \\
\hline Energy Production (E) & 1,650 per kW per year \\
\hline System Life (L) & 30 years \\
\hline \multicolumn{2}{|l|}{ PV Market Estimate } \\
\hline Installed PV Capacity $\left(Q_{0}\right)$ & $5.00 \mathrm{GW}$ \\
\hline Annual PV Sales & 1.50 GW per year \\
\hline Growth in Sales & $20 \%$ per year \\
\hline Progress Ratio (PR) & $82 \%$ \\
\hline \multicolumn{2}{|l|}{ General } \\
\hline Discount Rate (r) & $10 \%$ \\
\hline
\end{tabular}

\footnotetext{
${ }^{37}$ The price is assumed to be the price a commercial customer would pay after a 30 percent federal tax credit.
} 
Table 9. PBI calculations.

\begin{tabular}{|l|c|c|c|c|c|}
\hline & $\begin{array}{c}\text { Cumulative PV } \\
\text { Capacity (GW) }\end{array}$ & $\begin{array}{c}\text { Annual PV } \\
\text { Sales (GW) }\end{array}$ & $\begin{array}{c}\text { Effective PV } \\
\text { System Price }\end{array}$ & $\begin{array}{c}\text { Utility } \\
\text { Savings }\end{array}$ & PBI Rate \\
\hline $\mathbf{2 0 0 7}$ & 5.0 & 1.5 & $\$ 6,000$ & $\$ 0.12$ & $\mathbf{\$ 0 . 4 7}$ \\
$\mathbf{2 0 0 8}$ & 6.5 & 1.8 & $\$ 5,566$ & $\$ 0.12$ & $\mathbf{\$ 0 . 4 1}$ \\
\hline $\mathbf{2 0 0 9}$ & 8.3 & 2.2 & $\$ 5,190$ & $\$ 0.13$ & $\mathbf{\$ 0 . 3 6}$ \\
$\mathbf{2 0 1 0}$ & 10.5 & 2.6 & $\$ 4,857$ & $\$ 0.13$ & $\mathbf{\$ 0 . 3 2}$ \\
\hline $\mathbf{2 0 1 1}$ & 13.1 & 3.1 & $\$ 4,559$ & $\$ 0.14$ & $\mathbf{\$ 0 . 2 8}$ \\
\hline $\mathbf{2 0 1 2}$ & 16.2 & 3.7 & $\$ 4,288$ & $\$ 0.14$ & $\mathbf{\$ 0 . 2 5}$ \\
\hline $\mathbf{2 0 1 3}$ & 19.9 & 4.5 & $\$ 4,040$ & $\$ 0.14$ & $\mathbf{\$ 0 . 2 2}$ \\
\hline $\mathbf{2 0 1 4}$ & 24.4 & 5.4 & $\$ 3,812$ & $\$ 0.15$ & $\mathbf{\$ 0 . 2 0}$ \\
\hline $\mathbf{2 0 1 5}$ & 29.7 & 6.4 & $\$ 3,601$ & $\$ 0.15$ & $\mathbf{\$ 0 . 1 8}$ \\
\hline $\mathbf{2 0 1 6}$ & 36.2 & 7.7 & $\$ 3,404$ & $\$ 0.16$ & $\mathbf{\$ 0 . 1 5}$ \\
\hline $\mathbf{2 0 1 7}$ & 43.9 & 9.3 & $\$ 3,220$ & $\$ 0.16$ & $\mathbf{\$ 0 . 1 3}$ \\
\hline $\mathbf{2 0 1 8}$ & 53.2 & 11.1 & $\$ 3,048$ & $\$ 0.17$ & $\mathbf{\$ 0 . 1 1}$ \\
\hline $\mathbf{2 0 1 9}$ & 64.4 & 13.4 & $\$ 2,887$ & $\$ 0.17$ & $\mathbf{\$ 0 . 1 0}$ \\
\hline $\mathbf{2 0 2 0}$ & 77.7 & 16.0 & $\$ 2,735$ & $\$ 0.18$ & $\mathbf{\$ 0 . 0 0}$ \\
\hline $\mathbf{2 0 2 1}$ & 93.8 & 19.3 & $\$ 2,592$ & $\$ 0.18$ & $\mathbf{\$ 0 . 0 0}$ \\
\hline $\mathbf{2 0 2 2}$ & 113.1 & 23.1 & $\$ 2,457$ & $\$ 0.19$ & $\mathbf{\$ 0 . 0 0}$ \\
\hline $\mathbf{2 0 2 3}$ & 136.2 & 27.7 & $\$ 2,330$ & $\$ 0.19$ & $\mathbf{\$ 0 . 0 0}$ \\
\hline $\mathbf{2 0 2 4}$ & 163.9 & 33.3 & $\$ 2,209$ & $\$ 0.20$ & $\mathbf{\$ 0 . 0 0}$ \\
\hline $\mathbf{2 0 2 5}$ & 197.2 & 39.9 & $\$ 2,095$ & $\$ 0.20$ & $\mathbf{\$ 0 . 0 0}$ \\
\hline $\mathbf{2 0 2 6}$ & 237.1 & 47.9 & $\$ 1,988$ & $\$ 0.21$ & $\mathbf{\$ 0 . 0 0}$ \\
\hline
\end{tabular}
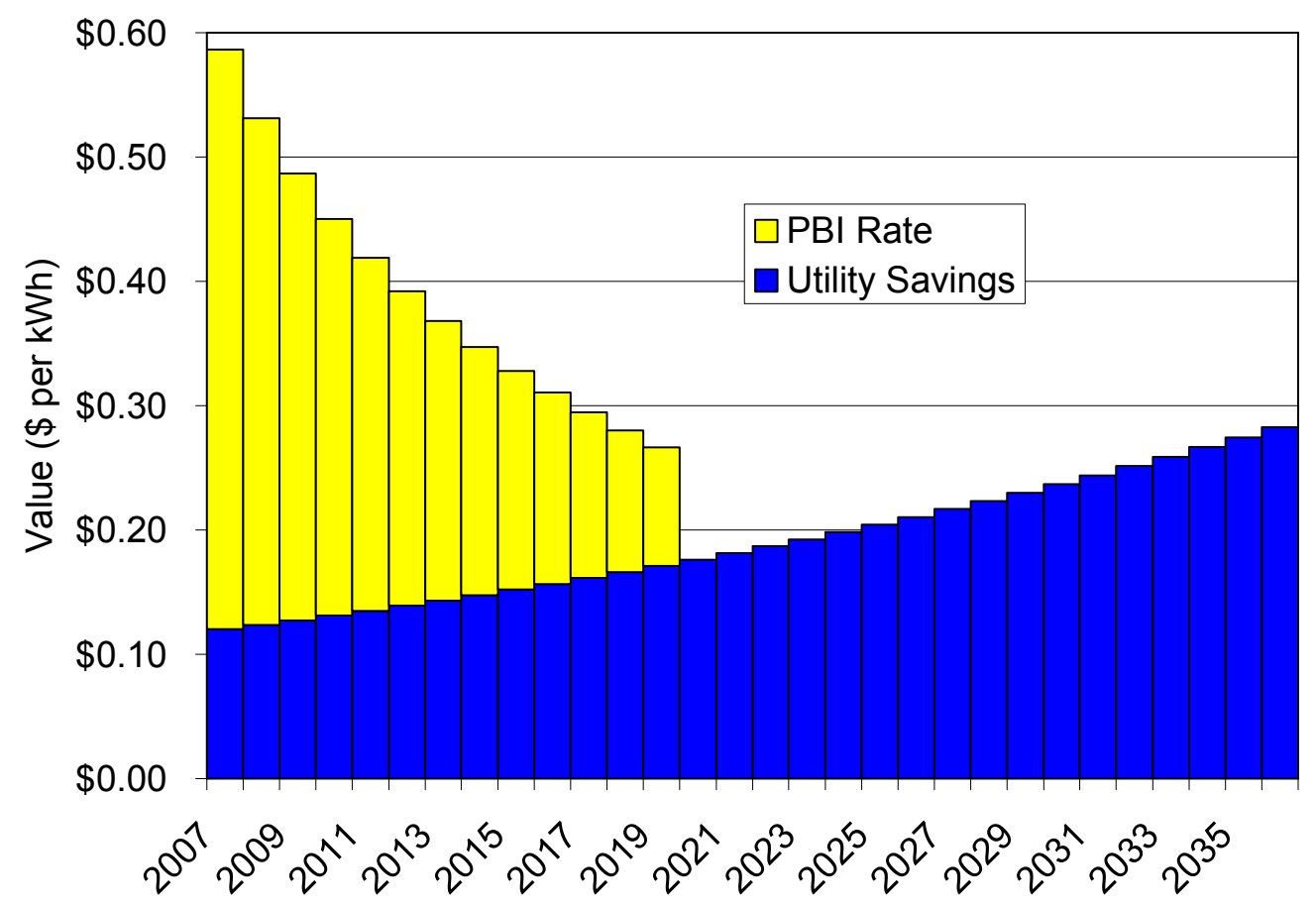

Figure 13. Total value versus year.

The results of this analysis can be verified by demonstrating that the customer is economically indifferent between investing and waiting during each year using the PBI 
structure specified in Table 9. In order to do this, the utility bill savings are added to the PBI rate and then multiplied by the PV system output to give the annual benefits. The results are shown in Table $\mathbf{1 0 .}$

Table 10. Verification of customer timing indifference.

\begin{tabular}{|c|c|c|c|c|c|}
\hline $\mathbf{2 0 0 7}$ & $\begin{array}{c}\text { Annual } \\
\text { Benefit }\end{array}$ & $\begin{array}{c}\text { 30-yr NPV } \\
\text { Savings }\end{array}$ & $\begin{array}{c}\text { Effective PV } \\
\text { System Price }\end{array}$ & $\begin{array}{c}\text { Savings - } \\
\text { Cost }\end{array}$ & $\begin{array}{c}\text { Discounted } \\
\text { Savings - Cost }\end{array}$ \\
\hline $\mathbf{2 0 0 8}$ & $\$ 868$ & $\$ 6,347$ & $\$ 6,000$ & $\$ 347$ & $\$ 347$ \\
\hline $\mathbf{2 0 0 9}$ & $\$ 803$ & $\$ 5,948$ & $\$ 5,566$ & $\$ 382$ & $\$ 347$ \\
\hline $\mathbf{2 0 1 0}$ & $\$ 743$ & $\$ 5,319$ & $\$ 4,857$ & $\$ 462$ & $\$ 347$ \\
\hline $\mathbf{2 0 1 1}$ & $\$ 691$ & $\$ 5,067$ & $\$ 4,559$ & $\$ 508$ & $\$ 347$ \\
\hline $\mathbf{2 0 1 2}$ & $\$ 647$ & $\$ 4,847$ & $\$ 4,288$ & $\$ 559$ & $\$ 347$ \\
\hline $\mathbf{2 0 1 3}$ & $\$ 608$ & $\$ 4,656$ & $\$ 4,040$ & $\$ 615$ & $\$ 347$ \\
\hline $\mathbf{2 0 1 4}$ & $\$ 573$ & $\$ 4,489$ & $\$ 3,812$ & $\$ 677$ & $\$ 347$ \\
\hline $\mathbf{2 0 1 5}$ & $\$ 541$ & $\$ 4,345$ & $\$ 3,601$ & $\$ 744$ & $\$ 347$ \\
\hline $\mathbf{2 0 1 6}$ & $\$ 512$ & $\$ 4,223$ & $\$ 3,404$ & $\$ 819$ & $\$ 347$ \\
\hline $\mathbf{2 0 1 7}$ & $\$ 486$ & $\$ 4,121$ & $\$ 3,220$ & $\$ 901$ & $\$ 347$ \\
\hline $\mathbf{2 0 1 8}$ & $\$ 462$ & $\$ 4,039$ & $\$ 3,048$ & $\$ 991$ & $\$ 347$ \\
\hline $\mathbf{2 0 1 9}$ & $\$ 440$ & $\$ 3,977$ & $\$ 2,887$ & $\$ 1,090$ & $\$ 347$ \\
\hline $\mathbf{2 0 2 0}$ & $\$ 291$ & $\$ 3,934$ & $\$ 2,735$ & $\$ 1,199$ & $\$ 347$ \\
\hline $\mathbf{2 0 2 1}$ & $\$ 299$ & $\$ 4,052$ & $\$ 2,592$ & $\$ 1,460$ & $\$ 384$ \\
\hline $\mathbf{2 0 2 2}$ & $\$ 308$ & $\$ 4,173$ & $\$ 2,457$ & $\$ 1,716$ & $\$ 411$ \\
\hline $\mathbf{2 0 2 3}$ & $\$ 318$ & $\$ 4,298$ & $\$ 2,330$ & $\$ 1,969$ & $\$ 428$ \\
\hline $\mathbf{2 0 2 4}$ & $\$ 327$ & $\$ 4,427$ & $\$ 2,209$ & $\$ 2,218$ & $\$ 439$ \\
\hline $\mathbf{2 0 2 5}$ & $\$ 337$ & $\$ 4,560$ & $\$ 2,095$ & $\$ 2,465$ & $\$ 443$ \\
\hline $\mathbf{2 0 2 6}$ & $\$ 347$ & $\$ 4,697$ & $\$ 1,988$ & $\$ 2,709$ & $\$ 443$ \\
\hline
\end{tabular}

For example, the benefits equal $\$ 968$ in 2007 when the sum of the utility savings $(12 \varnothing$ per $\mathrm{kWh})$ plus the PBI rate $(47 \varnothing$ per $\mathrm{kWh})$ is multiplied by the annual output $(1,650 \mathrm{kWh}$ per installed $\mathrm{kW})$. This is repeated for each year as shown in the first column. The second column presents the 30 -year present value savings. The net present value to the customer in any particular year is the difference between the 30-year present value savings (second column) and the price (third column) and is presented in the fourth column. The final step is to discount future years to 2007 (fifth column).

The table shows that the net present value of the investment from the perspective of 2007 is constant during all years that the PBI is offered. This confirms that the customer is economically indifferent between investing immediately and investing at any time during the next 12 years when the PBI is offered.

Notice also that the discounted savings minus cost is constant until after year 13, the point at which the cost-effectiveness test is satisfied. 


\section{Appendix E: Incentive Design That Shapes Market Demand}

Appendix D derived an incentive design that maintains a constant level of costeffectiveness for all customers entering the program at any point over its duration. This appendix derives an incentive design that maintains a steady incentive decline based on program goals. It uses the CSI program as an example of how this is applied (note that results are presented in units of system-AC).

\section{Analysis}

One approach to incentive design is to assume that the incentive is going to decline at a steady rate. This appendix begins with two assumptions: (1) the incentive rate declines linearly each year and (2) the market is growing at an exponential rate. Suppose that the year in which the PV is cost-competitive without an incentive is estimated to occur in year $\mathrm{T}$. Mathematically, these two assumptions mean that at any time $t$ less that $\mathrm{T}$, the incentive equals:

$$
I_{t}=I_{0}\left[1-\frac{t}{T}\right]
$$

The volume at time $t$ equals:

$V_{t}=V_{0}(1+g)^{t}$

where $g$ is the annual market growth rate (\%)

\section{Total Volume}

Since the market volume is growing at exponential rate as defined in Equation (12), the total volume installed over the life of the program can be determined. Let $\mathrm{V}_{0}$ represent the volume that will be installed in year $0, V_{1}$ represent the volume that will be installed in year 1, etc. The total volume installed over the life of the program equals the sum of each annual value until the year before systems become cost-effective without any incentive.

Total Volume $=\sum_{t=0}^{T-1} V_{t}$

Substituting Equation (12) into Equation (13) and solving, it can be shown that the total volume equals

Total Volume $=V_{0}\left[\frac{(1+g)^{T}-1}{g}\right]$ for $g \neq 0$

Equation (14) can be solved for the first year volume so that the total volume in conjunction with the growth rate is used to determine what the first year volume must be. 
$V_{0}=[$ Total Volume $]\left[\frac{g}{(1+g)^{T}-1}\right]$

\section{Incentive Budget}

Most incentive programs are constrained by the annual budgets they have available to spend over the life of the program. The total budget is calculated as the sum of the incentive rate times the annual volume summed over the life of the program.

Total Budget $=\sum_{t=0}^{T-1} I_{t} V_{t}$

Substituting for the definition of incentive at time $t$ in Equation (11) and volume at time $t$ in Equation (12), and then simplifying, the total budget equals

Total Budget $=\left(I_{0} V_{0}\right)\left[\sum_{t=0}^{T-1}\left(1-\frac{t}{T}\right)(1+g)^{t}\right]$

Then, solving for the first year's incentive:

$I_{0}=$ Total Budget $\left[\frac{1}{V_{0}}\right]\left[\frac{1}{\sum_{t=0}^{T-1}\left(1-\frac{t}{T}\right)(1+g)^{t}}\right]$

Substituting for the first year volume in Equation (15), the first year incentive equals

$$
I_{0}=\left[\frac{\text { Total Budget }}{\text { Total Volume }}\right]\left[\frac{(1+g)^{T}-1}{g}\right]\left[\frac{1}{\left(\sum_{t=0}^{T-1}\left(1-\frac{t}{T}\right)(1+g)^{t}\right)}\right]
$$

\section{Summary}

The key equations that have been developed include the volume over time, the incentive over time, the first year volume, and the first year incentive. These equations are summarized below. 
$V_{t}=V_{0}(1+g)^{t}$

$I_{t}=I_{0}\left[1-\frac{t}{T}\right]$ for $t<T$, else 0

where:

$V_{0}=[$ Total Volume $]\left[\frac{g}{(1+g)^{T}-1}\right]$

$I_{0}=\left[\frac{\text { Total Budget }}{\text { Total Volume }}\right]\left[\frac{(1+g)^{T}-1}{g}\right]\left[\frac{1}{\left(\sum_{t=0}^{T-1}\left(1-\frac{t}{T}\right)(1+g)^{t}\right)}\right]$

$g=$ Annual Market Growth Rate (\%)

$T=$ Years to Cost - Effectiveness with no incentive

One of the most important things to notice about Equation (20) is that the entire incentive structure is specified by four inputs: total budget, total volume, market growth rate, and years to cost effectiveness.

\section{Equivalence of Calendar and Volume-Based Incentive Triggers}

The previous subsection assumed that the incentive rate declines linearly each year. There has been the recommendation in the industry, however, that a change in the incentive should be triggered on a volume basis rather than a calendar basis.

This subsection demonstrates that the results presented in Equation (20) are applicable to a volume-based trigger when the incentive rate is linearly related to the natural log of the market volume, a recommendation that has been implicitly made by a number of parties. $^{38}$ That is, the incentive rate at time $\mathrm{t}\left(I_{t}\right)$ equals some slope $(m)$ times the natural $\log$ of the volume at that same time $\left(V_{t}\right)$ plus a y-intercept $(b)$.

$I_{t}=m \ln \left(V_{t}\right)+b$

Two sets of points are required to solve the equation for a line. Assume that one set is based on the start of the program (time $t=0$ ) and the other set is at time $\mathrm{T}$ at the end of the program when the incentive rate is 0 . The solution is:

$I_{t}=I_{0}+\left[\frac{0-I_{0}}{\ln \left(V_{T}\right)-\ln \left(V_{0}\right)}\right]\left[\ln \left(V_{t}\right)-\ln \left(V_{0}\right)\right]$

\footnotetext{
${ }^{38}$ The linearly relationship between the incentive rate and the logarithm of the market volume is an implicit recommendation that has been made by a number of parties, one of which is the Joint Solar Parties filing in the CSI program [13].
} 
Equation (12) can be substituted into Equation (22) and simplified.

$$
\begin{aligned}
I_{t} & =I_{0}+\left\{\frac{-I_{0}}{\ln \left[V_{0}(1+g)^{T}\right]-\ln \left(V_{0}\right)}\right\}\left\{\ln \left[V_{0}(1+g)^{t}\right]-\ln \left(V_{0}\right)\right\} \\
& =I_{0}+\left\{\frac{-I_{0}}{\ln \left(V_{0}\right)+\ln \left[(1+g)^{T}\right]-\ln \left(V_{0}\right)}\right\}\left\{\ln \left(V_{0}\right)+\ln \left[(1+g)^{t}\right]-\ln \left(V_{0}\right)\right\} \\
& =I_{0}-I_{0}\left\{\frac{\ln \left[(1+g)^{t}\right]}{\ln \left[(1+g)^{T}\right]}\right\} \\
& =I_{0}-I_{0}\left\{\frac{t \ln (1+g)}{T \ln (1+g)}\right\} \\
& =I_{0}\left[1-\frac{t}{T}\right]
\end{aligned}
$$

The result is that Equation (23) is identical to Equation (11), the assumption that the incentive is declining linearly over time. That is, assuming that the incentive is linearly related to the natural log of the market volume is analogous to assuming that the incentive is declining linearly over time when the market is growing at an exponential rate.

\section{Results}

The full incentive structure can be specified with the analytical approach summarized in Equation (20). Consider an example using the CSI program and the Joint Parties filing.

Suppose that the only things known about the program are as follows:

- Systems will be cost effective in 10 years without incentives $(T=10)$

- The market will grow at a rate of 35 percent per year $(\mathrm{g}=0.35)$

- The program goal is to install 2,295 $\mathrm{MW}_{\mathrm{AC}}$ of PV (Cumulative Volume $=2295$ this should produce the equivalent amount of energy as 2,550 $\left.\mathrm{MW}_{\mathrm{AC}-\mathrm{CEC}}\right)$

- The total incentive budget is $85 \%$ of $\$ 2,500$ Million or $\$ 2,125$ Million (Budget = 2125)

Table 11 presents the incentive structure calculated using Equation (20) and Figure 14 presents the incentive administered on a volume basis as compared to the Joint Filing proposed incentive structure. While not exact, the results that are generated through the use of four input variables are comparable to the incentive structure proposed by the Joint Parties. 
Table 11. Incentive schedule.

$\begin{array}{ccccc} & \text { Incentive (\$/Watt) } & \text { Volume (MW) } & \text { Growth Rate } & \text { Budget (\$M) } \\ 2007 & \$ 2.99 & 42 & & \$ 117 \\ 2008 & \$ 2.69 & 57 & 35 \% & \$ 142 \\ 2009 & \$ 2.39 & 77 & 35 \% & \$ 170 \\ 2010 & \$ 2.09 & 103 & 35 \% & \$ 201 \\ 2011 & \$ 1.79 & 140 & 35 \% & \$ 233 \\ 2012 & \$ 1.49 & 189 & 35 \% & \$ 262 \\ 2013 & \$ 1.19 & 254 & 35 \% & \$ 283 \\ 2014 & \$ 0.90 & 344 & 35 \% & \$ 286 \\ 2015 & \$ 0.60 & 464 & 35 \% & \$ 258 \\ 2016 & \$ 0.30 & 626 & 35 \% & \$ 174 \\ & & & & \\ \text { Total } & & 2,295 & & \$ 2,125\end{array}$

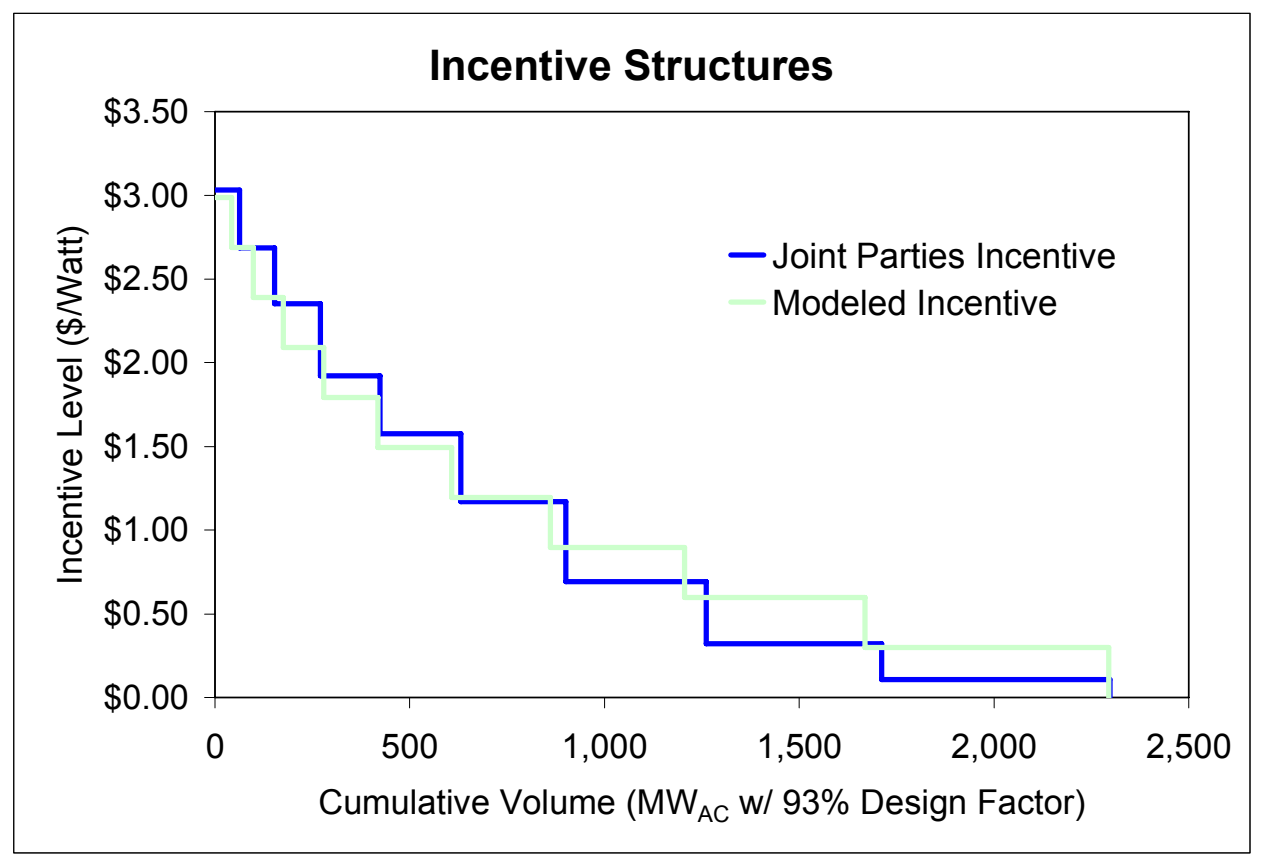

Figure 14. Incentive administered on a volume basis for model and Joint Filing results.

(Note: results are presented in system AC units, not AC-CEC units). 


\section{Conclusions}

This appendix derived an analytical model to design an incentive structure. ${ }^{39}$ The model is based on two assumptions: incentives are declining linearly (or incentive rates should be linearly related to the natural $\log$ of the annual sales) and annual PV sales grow at an exponential rate.

Several results can be derived based on these assumptions.

1. The incentive trigger mechanism can be either calendar-based or volume-based.

2. The complete incentive structure and trigger mechanisms are specified by four input parameters:

a. Total PV installations (MW) over the life of the program.

b. Total program budget $(\$ M)$.

c. Years until cost-effectiveness is reached without incentives.

d. Annual growth of program participation.

${ }^{39}$ This model can be applied to other technology incentive programs as well. 


\section{Appendix F: EPBB Incentive Calculation}

\section{Introduction}

The EPBB incentive is one of the structures that has been identified in this Handbook. Two different formulas can be used to calculate the EPBB. This appendix reviews the strengths and weaknesses of the two formulas. It also provides some cautionary notes that need to be observed when a program is transitioning from a CBB to an EPBB incentive.

\section{Analysis}

A straightforward way to calculate an EPBB incentive is to define a baseline energy production incentive rate ( $\$$ per $\mathrm{kWh})$ and multiply it by the simulated output of the designed system over some period of time.

$$
\text { Incentive }(\$)=\text { Energy Rate }(\$ / k W h) \times \text { Simulated Output for Designed System }(\mathrm{kWh})
$$

While this approach has intuitive appeal because of its simplicity, it has limitations because performance simulations are inherently subject to error, making it difficult to validate results without extended field testing. For this reason, it is desirable to derive a form of Equation (24) that minimizes simulation error and provides for direct field verification over a short period of time.

First, consider how one would establish the Energy Rate $(\$$ per $\mathrm{kWh})$ presented in Equation (24). One needs to set an Incentive Rate (\$ per $\left.\mathrm{kW}_{\mathrm{AC}}\right)$, multiply it by the System Rating $\left(\mathrm{kW}_{\mathrm{AC}}\right)$, and divide the result by the simulated output $(\mathrm{kWh})$ for some Reference System over a given time period (typically a year should be sufficient).

That is,

$$
\text { Energy Rate }(\$ / k W h)=\frac{\text { Incentive Rate }\left(\$ / \mathrm{kW}_{\mathrm{AC}}\right) \times \operatorname{System} \operatorname{Rating}\left(\mathrm{kW}_{\mathrm{AC}}\right)}{\text { Simulated Output for Reference System }(\mathrm{kWh})}
$$

Substituting this back in to Equation (24), the Incentive equals the Energy Rate times the Simulated Output for Designed System (kWh).

Incentive $(\$)=\frac{\text { Incentive Rate }\left(\$ / \mathrm{kW}_{\mathrm{AC}}\right) \times \text { System Rating }\left(\mathrm{kW}_{\mathrm{AC}}\right)}{\text { Simulated Ouptut for Reference System }(\mathrm{kWh})} x \operatorname{Simulated}$ Output for Designed System $(\mathrm{kWh})$

The terms in this equation, however, can be rearranged as

Incentive $(\$)=$ Incentive Rate $\left(\$ / \mathrm{kW}_{\mathrm{AC}}\right) \times$ System Rating $\left(\mathrm{kW}_{\mathrm{AC}}\right) \times \frac{\text { Simulated Output for Designed System }(\mathrm{kWh})}{\text { Simulated Output for Reference System }(\mathrm{kWh})}$

This can be written as 
Incentive $(\$)=$ Incentive Rate $\left(\$ / \mathrm{kW}_{A C}\right) \times \operatorname{System} \operatorname{Rating}\left(\mathrm{kW}_{A C}\right) \times$ Design Factor

where

Design Factor $=\frac{\text { Simulated Output for Actual System }(\mathrm{kWh})}{\text { Simulated Output for Reference System }(\mathrm{kWh})}$

Equation (25) is identical to the CPUC's proposed EPBB calculation when the Reference System is Fixed $30^{\circ}$ South-facing with no shading [12].

\section{Discussion}

While Equation (25) is more complex than Equation (24), it overcomes the key limitations of Equation (24) and offers a number of advantages as discussed below.

\section{Potential Performance Issues Are Disaggregated}

All of the performance factors and sources of error are lumped into a single term (the Simulated Output for Designed System) in Equation (24). Equation (25), on the other hand, disaggregates the performance factors into two terms. Performance due to system rating issues is captured by the System Rating term; performance due to system orientation and shading issues (and location if the program chooses to include this) are captured by the Design Factor term.

\section{System Rating can be Verified}

With Equation (25), the System Rating has the potential to be directly verifiable through field measurements. This is a fundamental feature that has been lacking throughout most capacity based incentive structures: most are operated using rating conventions that rely on calculated values but cannot be directly verified using field measurements.

The System Rating in Equation (25) captures all of the losses and inefficiencies that make up the AC rating of the system. Rating inaccuracies for PV modules and inverters, internal wiring losses and other losses are captured by the System Rating. If desired, the incentive granting agency can specify test procedures to directly measure the System Rating.

\section{Design Factor can be Verified}

The parameters used in the Design Factor can be verified by a simple visual inspection of the system. The inspection would confirm that it is installed with the planned orientation and with the shading factors as specified by the applicant.

\section{High Performance Systems are Rewarded}

Since the EPBB incentive is tied to the System Rating and Design Factor, investors would take care to ensure that these factors are given due consideration. The incentive would help to ensure that efficient modules and inverters are used, that internal wiring losses are minimized, that design orientations more closely match the reference system, 
and shading is minimized. These factors are likely to lead manufacturers to market more efficient equipment and to encourage system installers to design more effective systems.

\section{The Calculation is Less Susceptible to Modeling Error}

In Equation (24), it is critical that both the model and weather data used in the incentive calculation be highly accurate. Paying an incentive that is highly dependent on model or weather data accuracy leads to uncertainty among investors who may challenge model and data accuracy.

This situation is much more manageable with EPBB programs using Equation (25). Since the Design Factor is the ratio of two simulated quantities, relative model and data accuracy is of importance, not absolute accuracy. The Design Factor determines what percent of annual energy production the actual design should have relative to the Reference System. Since the Design Factor uses the same model and same weather data for both the numerator and the denominator, modeling and data inaccuracies are less critical. $^{40}$

The form of the Design Factor in Equation (25) normalizes the results relative to the Reference System. Bias in any element of the modeling would be present in both the numerator and the denominator, tending to cancel out in the ratio. For example, if the simulation were based on an optimistic weather data set, the estimated performance of both the actual System and Reference System would be increased, and the individual errors would tend to cancel in the ratio.

\section{Transitioning from CBB to EPBB}

If a program is transitioning from a $\mathrm{CBB}$ to the $\mathrm{EPBB}$ incentive structure, two major factors need to be accounted for. First, most CBB incentives use a component-based rating while it is recommended that the EPBB calculation use a system $\mathrm{AC}$ rating. Second, the EPBB uses a Design Factor that introduces a penalty for all systems that have lower energy production than the Reference System.

These two factors can be address by either (1) increasing the Incentive Rate or (2) defining a sub-optimal Reference System. In order to illustrate how this can be done, an example is presented using a program that is transitioning from a CBB to an EPBB.

\section{Adjustment Option: Increase Incentive}

The first option is to increase the incentive. Suppose that the average PV system installed in the program produces 94 percent as much energy as the Reference System. Suppose that a customer installs a $100 \mathrm{~kW}_{\mathrm{AC}-\mathrm{CEC}}$ and the program wants to maintain economic parity with the existing incentive of $\$ 2.50 /$ Watt $_{\mathrm{AC}-\mathrm{CEC} \text {. }}$

As presented in Table 12, the customer would receive $\$ 250,000$ under the current CBB program. What would it require for a customer to be equally well off under the EPBB structure? A $100 \mathrm{~kW}_{\mathrm{AC}-\mathrm{CEC}}$ is equivalent to $90 \mathrm{~kW}_{\mathrm{AC}}$ and the Design Factor is 94 percent.

\footnotetext{
40 This is true when the Design Factor does not incorporate a location element.
} 
As a result, the EPBB Incentive Rate needs to increase by 18 percent to $\$ 2.96 / \mathrm{Watt}_{\mathrm{AC}}$ to provide the customer with the same economic benefit as the $\mathrm{CBB}$ incentive.

Table 12. Incentive comparisons (higher Incentive Rate).

\author{
Intentive Rate (\$/Watt) \\ Rating Calculation \\ Number of Modules \\ PV PTC Module Rating (W) \\ Inverter Efficiency \\ Other Losses
}

Estimated Rating (kW)

Design Factor

Incentive Amount (\$K)

\section{SGIP Program}

$\$ 2.50$

1,000

105.2

$95 \%$

99.9

$-$

$\$ 250$
EPBB Staff Proposal w/ Higher Incentive Rate $\$ 2.96$

1,000

105.2

$95 \%$

$90 \%$

89.9

$94 \%$

$\$ 250$

\section{Adjustment Option: Use Different Reference System}

The second option is to use a different reference system. An analysis was performed using the Clean Power Estimator for a system in San Jose, CA. ${ }^{41}$ A fixed $30^{\circ}$ southfacing system with no shading is estimated to have a DC-based capacity factor of 16 percent. A recent report by the California Energy Commission, however, found that the average DC-based capacity factor for systems including the effect of orientation and shading was 15 percent [7]. Thus, based on the CEC report, it appears that systems have an average of 6 percent design losses. When the 6 percent design losses are combined with the 10 percent rating losses, the result is a combined loss of 15 percent.

In order to compensate for this loss through the Design Factor, the Reference System needs to be chosen to have an expected output that is 85 percent of a fixed $30^{\circ}$ southfacing system with no shading. ${ }^{42}$ Analysis using the Clean Power Estimator suggests that one system that fits this description is a horizontal system with 5 percent shading losses.

The capacity factors for various system configurations are presented in the top part of Table 13. The Design Factors using a horizontal system with 5 percent shading losses as the Reference System are presented in the bottom part of Table 13.

\footnotetext{
${ }^{41} \mathrm{PV}$ Watts is another on-line simulation tool. It does not, however, have the capability of performing a shading analysis as is incorporated into the Clean Power Estimator (http://www.njcep.com/html/estimator_f.html). The Clean Power Estimator was run with 10 percent PV Output Adjustment to be consistent with PV Watts 0.77 derating factor.

$421 / 0.85=1.18$.
} 
Table 13. Capacity factor and design factor

(San Jose, CA using Clean Power Estimator).

Capacity Factor (Based on DC Rating)

\begin{tabular}{|crrrrr}
\multicolumn{7}{c}{ Degrees of Shading } & & & \\
Tilt & $\mathbf{0}$ & $\mathbf{5}$ & $\mathbf{1 0}$ & $\mathbf{1 5}$ & $\mathbf{2 0}$ \\
Horizontal & $14.2 \%$ & $14.2 \%$ & $14.1 \%$ & $14.0 \%$ & $13.5 \%$ \\
$\mathbf{1 0}$ & $15.2 \%$ & $15.2 \%$ & $15.0 \%$ & $14.8 \%$ & $14.3 \%$ \\
$\mathbf{2 0}$ & $15.8 \%$ & $15.8 \%$ & $15.6 \%$ & $15.3 \%$ & $14.7 \%$ \\
$\mathbf{3 0}$ & $16.0 \%$ & $15.9 \%$ & $15.7 \%$ & $15.4 \%$ & $14.8 \%$
\end{tabular}

Design Factor (Reference: Horizontal System, $5 \%$ or $20^{\circ}$ Shading)

\begin{tabular}{|c|c|c|c|c|c|}
\hline \multicolumn{6}{|c|}{ Degrees of Shading } \\
\hline Tilt & 0 & 5 & 10 & 15 & 20 \\
\hline Horizontal & $105 \%$ & $105 \%$ & $104 \%$ & $103 \%$ & $100 \%$ \\
\hline 10 & $112 \%$ & $112 \%$ & $111 \%$ & $109 \%$ & $106 \%$ \\
\hline 20 & $117 \%$ & $116 \%$ & $115 \%$ & $113 \%$ & $109 \%$ \\
\hline 30 & $118 \%$ & $118 \%$ & $116 \%$ & $114 \%$ & $109 \%$ \\
\hline
\end{tabular}

To illustrate how the calculations work, assume that a customer installs a fixed $10^{\circ}$ southfacing system with minor shading (i.e., a system with a 15 percent DC capacity factor). As presented in Table 13, the Design Factor for this system is 111 percent. Assume that

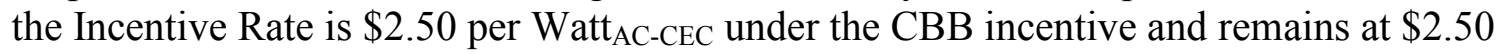
per Watt ${ }_{A C}$ under the EPBB incentive program. Table 14 demonstrates that the total incentive is $\$ 250 \mathrm{~K}$ for both structures.

Table 14. Incentive comparisons (Reference System is horizontal w/ shading).

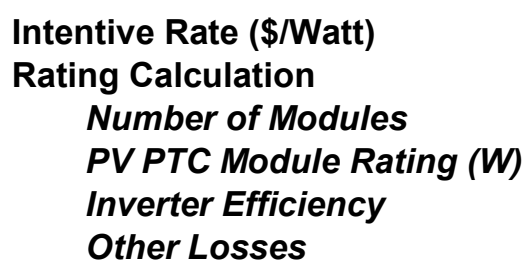

EPBB Staff Proposal w/

SGIP Program

$\$ 2.50$

1,000

105.2

95\%

-

99.9

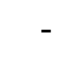

$\$ 250$
Modified Design Factor

$\$ 2.50$

1,000

105.2

$95 \%$

$90 \%$

89.9

$111 \%$

$\$ 250$ 


\section{Conclusions}

The EPBB incentive allows the market to transition to an incentive that is performance based. The EPBB structure creates an incentive calculation that has the potential to provide some (but not all) of the benefits of a PBI structure. In particular,

1. Short duration field testing (as yet to be fully specified) and visual inspection can verify the accuracy of critical factors that affect energy production

2. The incentive can be adjusted for the expected energy production of the system by using a verified system rating (thus promoting efficient components and good installations)

3. The incentive is adjusted for expected energy production of the system due to orientation and shading (thus promoting effective system design)

4. The incentive calculation procedure is not highly sensitive to modeling and data accuracy (thus resulting in greater program objectivity)

Transitioning from a CBB structure to the EPBB incentive structure may result in a reduction in the incentive for fixed $\mathrm{PV}$ systems when compared to a $\mathrm{CBB}$ program. If the goal is to retain a total incentive amount that is unchanged compared to existing CBB incentive levels, an adjustment needs to be made to the EPBB incentive calculation. This can be accomplished by modifying either the Incentive Rate or the Reference System. 


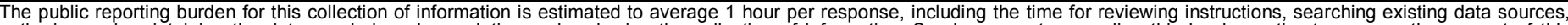

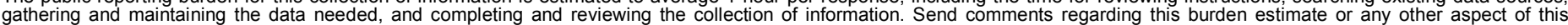

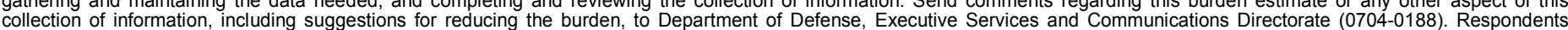

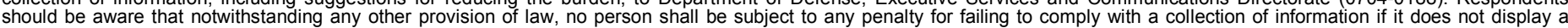

should be aware that notwithstanding

PLEASE DO NOT RETURN YOUR FORM TO THE ABOVE ORGANIZATION.

\begin{tabular}{ll|l} 
1. & REPORT DATE $(D D-M M-Y Y Y Y)$ \\
& December 2006 & $\begin{array}{l}\text { REPORT TYPE } \\
\text { Subcontract Report }\end{array}$ \\
\hline 4. & TITLE AND SUBTITLE
\end{tabular}

3. DATES COVERED (From - To)

Photovoltaic Incentive Design Handbook

DE-AC36-99-GO10337

5b. GRANT NUMBER

5c. PROGRAM ELEMENT NUMBER

6. AUTHOR(S)

T.E. Hoff

5d. PROJECT NUMBER

NREL/SR-640-40845

5e. TASK NUMBER

PVC6.1301

5f. WORK UNIT NUMBER

7. PERFORMING ORGANIZATION NAME(S) AND ADDRESS(ES)

Clean Power Research

10 Glen Court

8. PERFORMING ORGANIZATION REPORT NUMBER

Napa, CA 94558

9. SPONSORING/MONITORING AGENCY NAME(S) AND ADDRESS(ES)

National Renewable Energy Laboratory

1617 Cole Blvd.

Golden, CO 80401-3393

ADC-6-66286-01

\section{DISTRIBUTION AVAILABILITY STATEMENT}

National Technical Information Service

U.S. Department of Commerce

5285 Port Royal Road

Springfield, VA 22161

13. SUPPLEMENTARY NOTES

NREL Technical Monitor: Robert Margolis

14. ABSTRACT (Maximum 200 Words)

Investments in customer-owned grid-connected photovoltaic (PV) energy systems are growing at a steady pace.

This is due, in part, to the availability of attractive economic incentives offered by public state agencies and utilities.

In the United States, these incentives have largely been upfront lump payments tied to the system capacity rating.

While capacity-based "buydowns" have stimulated the domestic PV market, they have been criticized for subsidizing systems with potentially poor energy performance. As a result, the industry has been forced to consider alternative incentive structures, particularly ones that pay based on long-term measured performance. The industry, however, lacks consensus in the debate over the tradeoffs between upfront incentive payments versus longer-term payments for energy delivery. This handbook is designed for agencies and utilities that offer or intend to offer incentive programs for customer-owned PV systems. Its purpose is to help select, design, and implement incentive programs that best meet programmatic goals. The handbook begins with a discussion of the various available incentive structures and then provides qualitative and quantitative tools necessary to design the most appropriate incentive structure. It concludes with program administration considerations.

15. SUBJECT TERMS

NREL; Clean Power Research; Solar Energy Technologeis Program; solar; PV; photovoltaics; performance based incentive; PBI; expected performance based buydown; EPBB; PV incentives; utilities; incentive programs; customers; California Solar Initiative; market demand; green tags; net metering; Robert Margolis.

\begin{tabular}{|l|l|l|l|l|}
\hline $\begin{array}{l}\text { 16. SECURITY CLASSIFICATION OF: } \\
\begin{array}{c}\text { a. REPORT } \\
\text { Unclassified }\end{array}\end{array}$ & $\begin{array}{c}\text { b. ABSTRACT } \\
\text { Unclassified }\end{array}$ & $\begin{array}{l}\text { c. THIS PAGE } \\
\text { Unclassified }\end{array}$ & $\begin{array}{c}\text { OF ABSTRACT } \\
\text { UL }\end{array}$ & $\begin{array}{c}\text { NUMBER } \\
\text { OF PAGES }\end{array}$ \\
\end{tabular}

19a. NAME OF RESPONSIBLE PERSON
19b. TELEPHONE NUMBER (Include area code)

